\title{
mTORC1 activation in podocytes is a critical step in the development of diabetic nephropathy in mice
}

\begin{abstract}
Ken Inoki, ${ }^{1,2,3}$ Hiroyuki Mori, ${ }^{2}$ Junying Wang, ${ }^{1}$ Tsukasa Suzuki, ${ }^{1}$ SungKi Hong, ${ }^{1}$ Sei Yoshida, ${ }^{1}$ Simone M. Blattner, ${ }^{3}$ Tsuneo Ikenoue, ${ }^{1}$ Markus A. Rüegg, ${ }^{4}$ Michael N. Hall, ${ }^{4}$ David J. Kwiatkowski, ${ }^{5}$ Maria P. Rastaldi, ${ }^{6}$ Tobias B. Huber, ${ }^{7,8}$ Matthias Kretzler, ${ }^{3}$ Lawrence B. Holzman, ${ }^{9}$ Roger C. Wiggins, ${ }^{3}$ and Kun-Liang Guan ${ }^{10}$

${ }^{1}$ Life Sciences Institute, ${ }^{2}$ Department of Molecular and Integrative Physiology, and ${ }^{3}$ Division of Nephrology, Department of Internal Medicine, University of Michigan, Ann Arbor, Michigan, USA. ${ }^{4 B i o z e n t r u m, ~ U n i v e r s i t y ~ o f ~ B a s e l, ~ B a s e l, ~ S w i t z e r l a n d . ~}{ }^{5}$ Translational Medicine Division, Department of Medicine, Brigham and Women's Hospital, Harvard Medical School, Boston, Massachusetts, USA. ${ }^{6}$ Renal Research Laboratory, Fondazione IRCCS Policlinico and Fondazione D'Amico, Milan, Italy. ${ }^{7}$ Renal Division, University Hospital Freiburg, Freiburg, Germany.

${ }^{8}$ Centre for Biological Signalling Studies (bioss), Albert-Ludwigs-University, Freiburg, Germany. ${ }^{9}$ Renal Electrolyte and Hypertension Division, University of Pennsylvania School of Medicine, Philadelphia, Pennsylvania, USA. ${ }^{10}$ Department of Pharmacology, Moores Cancer Center, UCSD, San Diego, California, USA.
\end{abstract}

\begin{abstract}
Diabetic nephropathy (DN) is among the most lethal complications that occur in type 1 and type 2 diabetics. Podocyte dysfunction is postulated to be a critical event associated with proteinuria and glomerulosclerosis in glomerular diseases including DN. However, molecular mechanisms of podocyte dysfunction in the development of DN are not well understood. Here we have shown that activity of mTOR complex 1 (mTORC1), a kinase that senses nutrient availability, was enhanced in the podocytes of diabetic animals. Further, podocytespecific mTORC1 activation induced by ablation of an upstream negative regulator (PcKOTsc1) recapitulated many DN features, including podocyte loss, glomerular basement membrane thickening, mesangial expansion, and proteinuria in nondiabetic young and adult mice. Abnormal mTORC1 activation caused mislocalization of slit diaphragm proteins and induced an epithelial-mesenchymal transition-like phenotypic switch with enhanced ER stress in podocytes. Conversely, reduction of ER stress with a chemical chaperone significantly protected against both the podocyte phenotypic switch and podocyte loss in PcKOTsc1 mice. Finally, genetic reduction of podocyte-specific $m$ TORC1 in diabetic animals suppressed the development of DN. These results indicate that mTORC1 activation in podocytes is a critical event in inducing DN and suggest that reduction of podocyte mTORC1 activity is a potential therapeutic strategy to prevent DN.
\end{abstract}

\section{Introduction}

Diabetic nephropathy (DN) is a complication associated with both type 1 and type 2 diabetes and is a major public health problem in modern society. Despite considerable attention from both clinicians and basic scientists, the prevalence of glomerulosclerosis and end-stage renal disease (ESRD) in diabetic patients is increasing dramatically (1). Thus, understanding the pathogenesis of DN is crucial to develop new therapies for its prevention and treatment.

Recent investigations have revealed that injuries to podocytes play a critical role in the development of many glomerular diseases including DN (2-4). These highly differentiated glomerular epithelial cells with their modified intercellular junctions (slit diaphragms) between interdigitating foot processes contribute to the filtration barrier, which prevents plasma proteins from being lost into the glomerular capillary filtrate. Mutation of genes that encode slit diaphragm proteins such as nephrin and podocin causes congenital glomerular diseases, with massive proteinuria associated with podocyte injury (5-7). Although molecular events underlying podocyte injury in metabolic glomerulopathies may differ from these genetic disorders, it has been postulated that podocyte dysfunction play a crucial role in the development of DN (8-10).

Conflict of interest: The authors have declared that no conflict of interest exists. Citation for this article: J Clin Invest. 2011;121(6):2181-2196. doi:10.1172/JCI44771
mTOR is an evolutionarily conserved protein kinase and forms two functional complexes, termed mTOR complex 1 (mTORC1) and mTORC2 (11). mTORC1 is a rapamycin-sensitive protein kinase complex and regulates a wide array of cellular processes including cell growth, proliferation, and autophagy in response to nutrients such as glucose, amino acids, and growth factors (12). In response to these stimuli, mTORC1 is activated by at least two families of ras-related small GTPases, Rheb and Rags $(13,14)$. Although the precise molecular mechanisms by which these small GTPases activate mTORC1 remain elusive, GTPbound Rheb (active form) directly binds and activates mTORC1 (15). Notably, active Rheb is suppressed by tuberous sclerosis complex (TSC) gene products. TSC is an inherited benign tumor syndrome characterized by the formation of multiple hamartomas in a wide array of organs $(16,17)$. Germline mutations in either the TSC1 or TSC2 tumor-suppressor gene cause TSC. TSC1 and TSC2 form a functional complex in which TSC2 has GTPaseactivating protein (GAP) activity toward Rheb, while TSC1 stabilizes TSC2. Thus, loss of either TSC1 or TSC2 causes cells and tissues to display constitutive mTORC1 activation, contributing to their tumor phenotype.

Recent studies have reported that systemic administration of rapamycin prevents the progression of $\mathrm{DN}$ in mouse models of both type 1 and type 2 diabetes (18-22). However, the molecular 
A $d b /+$ $d b / d b$
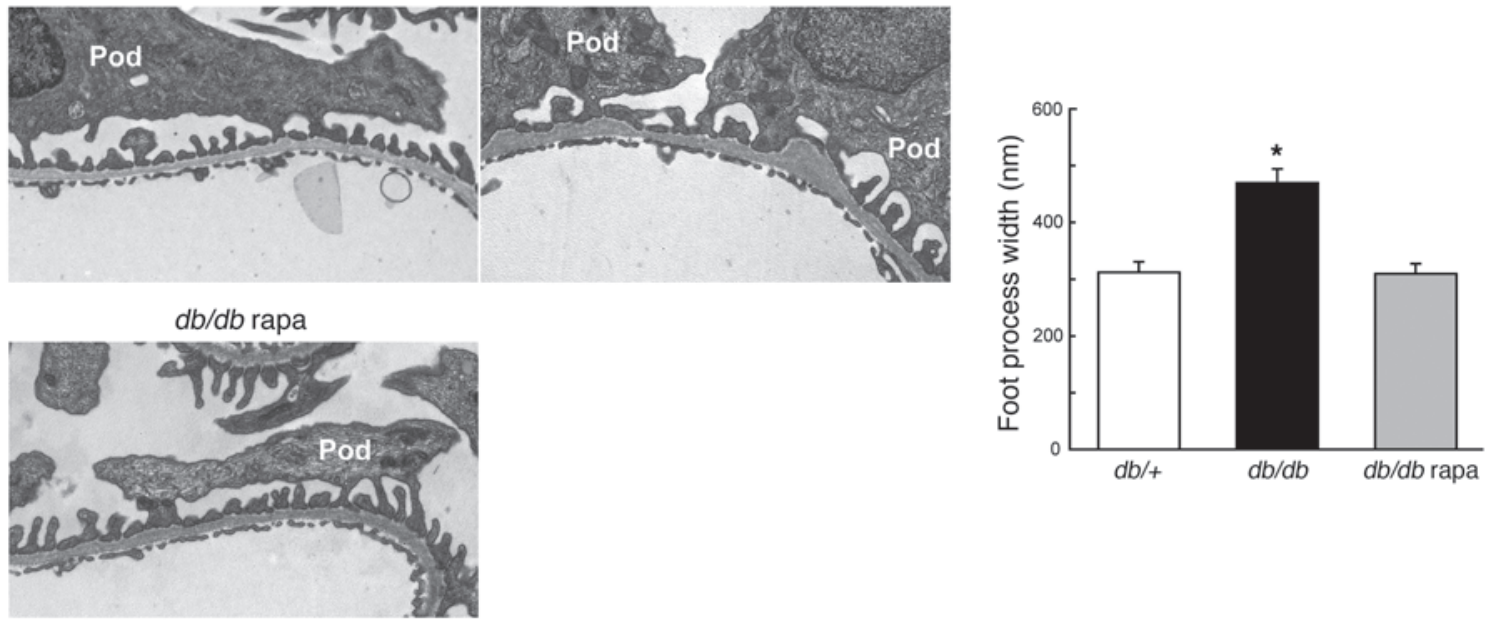

B

pS6 WT1
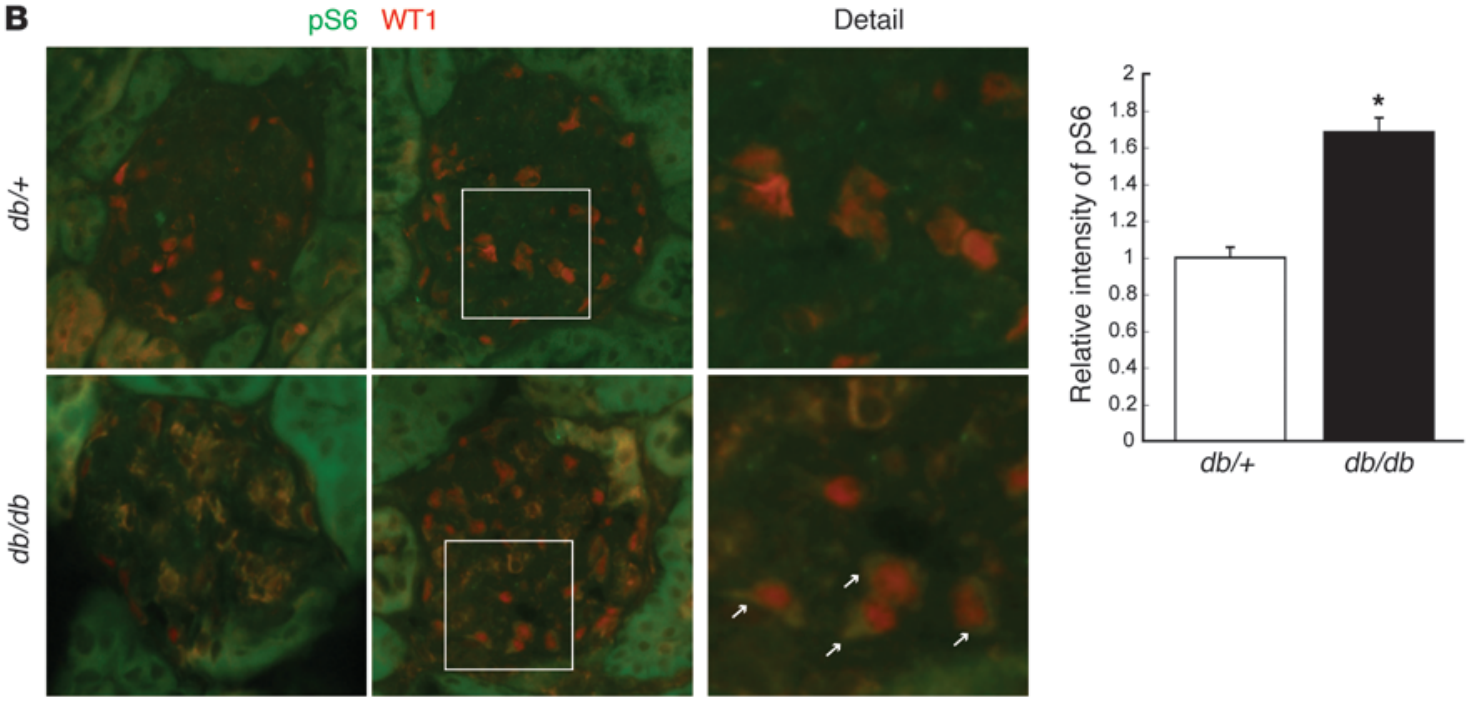

$d b / d b$

\section{Figure 1}

mTORC1 activation in podocytes, and prevention of podocyte morphological changes by rapamycin treatment in $d b / d b$ mice. (A) Foot process effacement in $d b / d b$ mice is blocked by rapamycin (rapa). Glomeruli from mice at 25 weeks of age with the indicated genotypes were examined by TEM. Foot process width at the level of slit diaphragm was measured (100 foot processes/glomerulus, 4 glomeruli/mouse, 3 male mice/group); ${ }^{*} P<0.001$ versus other groups, mean \pm SEM. Rapamycin treatment (1 mg/kg, i.p. injection, 3 times/week) was performed from 8 to 25 weeks of age. Pod, podocyte. (B) mTORC1 activity is enhanced in the podocytes of diabetic animals. Double staining with anti-phospho-S6 and anti-WT1 antibodies was performed on frozen sections from mice of the indicated genotypes at 12 weeks of age. The arrows indicate enhanced phospho-S6 signal in the cytoplasm of $d b / d b$ podocytes. Quantification of glomerular phospho-S6 (green) pixel density divided by glomerular area is shown. Data are expressed as fold induction (4 images per mouse, 3 male mice/group); ${ }^{*} P<0.001$, mean \pm SEM. Original magnification, $\times 13,500(\mathbf{A}) ; \times 400(\mathbf{B})$.

mechanism and site of action by which rapamycin prevents the development of DN are uncertain.

Here we report that podocyte-specific ITORC1 activation recapitulates many DN features, including podocyte injury, glomerular basement membrane (GBM) thickening, mesangial expansion, and proteinuria. mTORC1 activation in podocytes showed reversible structural and functional phenotypic changes that caused proteinuria, and continuous mTORC1 activation led to podocyte loss. Furthermore, genetic reduction of mTORC1 activity in podocytes by ablation of one allele of regulatory-associated protein of $\mathrm{mTOR}$ (Raptor; encoding RAPTOR), an essential component of mTORC1, significantly prevented the development of $\mathrm{DN}$ in diabetic mice.
These results indicate that site-specific activation of mTORC1 in podocytes plays a crucial role in the development of $\mathrm{DN}$.

\section{Results}

Activation of $m$ TORC1 in podocytes in DN. Systemic administration of rapamycin is known to prevent the development of $\mathrm{DN}$ in diabetic animals by unknown mechanisms (18-22). Rapamycin treatment prevented glomerular hypertrophy, GBM thickening, mesangial expansion (Supplemental Figure 1A; supplemental material available online with this article; doi:10.1172/JCI44771DS1), podocyte loss, macrophage infiltration, and albuminuria (Supplemental Figure $1 \mathrm{~B}$ ) without affecting blood glucose in $d b / d b$ mice, which is 
a common model for obesity-related type 2 diabetes (22). We also found that rapamycin treatment maintained the normal podocyte interdigitating foot process architecture, which was lost under diabetic conditions (Figure 1A). These data indicate that lowering mTORC1 activity in the diabetic animals also protects the architecture of filtration barriers that are damaged during the development of DN. To examine mTORC1 activity in glomerular cells, we measured the levels of S6 phosphorylation, a downstream target of mTORC1 that is frequently used as an in vivo indicator for mTORC1 activity. Although the intensity of S6 phosphorylation was much higher in the tubular regions compared with that in the glomeruli in both genotypes, we found that S6 phosphorylation in glomeruli was increased in $d b / d b$ mice compared with $d b /+$ mice (Figure 1B). Double staining with WT1, a podocyte nucleus maker, showed that S6 phosphorylation was enhanced in the cytoplasm of WT1-positive cells in $d b / d b$ mice, indicating that mTORC1 activity was indeed elevated in podocytes.

mTORC1 activation in podocytes causes mesangial expansion. To address whether activation of mTORC1 in podocytes contributes to podocyte injury and the development of glomerulopathy, we generated mice (PcKOTsc1) with a conditionally ablated Tsc1 gene in podocytes using a Cre expression cassette under the control of the Neph2 promoter (23). Because TSC1 is an upstream negative regulator of mTORC1, loss of TSC1 should result in activation of the mTORC1 pathway (24). Conventional Tsc1-KO mice die in embryonic stages due to cardiac and liver dysfunction (16), but PcKOTsc1 mice were born at normal Mendelian ratios and grew normally (Supplemental Figure 2A). We monitored mTORC1 activity over time by assaying the level of phospho-S6. Specific enhancement of phospho-S6 in podocytes was observed in PcKOTsc1 mice around 2 weeks after birth, suggesting that Cre recombination of the floxed Tsc1 gene was completed soon after birth (Supplemental Figure 2B). At 4 weeks of age, phosphorylation of S6 in the majority of PcKOTsc1 podocytes was dramatically enhanced, and rapamycin treatment attenuated this as expected, indicative of a high mTORC1 activity in podocytes of PcKOTsc1 mice (Figure 2A). Western blot analysis using glomerular proteins also showed that S6 was highly phosphorylated in a rapamycin-sensitive manner, whereas the levels of phosphorylation of Akt (Ser473), the site regulated by mTORC2 activity, was stable in PcKOTsc1 glomeruli (Figure 2B). PcKOTsc1 podocytes stained with WT1, a podocyte marker, were larger than those of wild-type mice (Figure 2A and Supplemental Figure 2C). We found that large amounts of eosin- and PAS-positive materials were present in the mesangial area (Figure 2A and Supplemental Figure 2, $\mathrm{D}$ and $\mathrm{E}$ ) of PcKOTsc1 mice. Furthermore, total glomerular cell number was decreased in PcKOTsc1 mice (Supplemental Figure $2 \mathrm{~F})$, indicating that the glomerular phenotype seen in PcKOTsc1 mice was not associated with cell proliferation. Again, these phenotypic changes were not observed in rapamycin-treated PcKOTsc1 glomeruli (Figure 2A and Supplemental Figure 2, C-F), suggesting that high mTORC1 activity in PcKOTsc1 podocytes contributed to mesangial expansion in this model. Consistent with these observations, both mRNA and protein levels of type IV collagen and fibronectin were significantly increased in PcKOTsc1 glomeruli (Figure $2, \mathrm{C}$ and D). Moreover, we also observed that mRNA and protein levels of TGF- $\beta 1$ were significantly enhanced (Supplemental Figure $2, \mathrm{G}$ and $\mathrm{H}$ ), whereas the protein expression but not amount of mRNA for angiotensin type 2 receptor (AT2R), which may have renoprotective functions, was reduced in PcKOTsc1 mouse glomeruli (Supplemental Figure 2, G and I) (25-27).
mTORC1 activation in podocytes causes podocyte injury and proteinuria. Next we monitored proteinuria in PcKOTsc1 mice. Consistent with the time course of mTORC1 activation in podocytes (Supplemental Figure 2B), PcKOTsc1 mice showed selective albuminuria starting at 2 weeks of age. The majority of PcKOTsc 1 mice showed massive and nonselective proteinuria around 3-4 weeks age (Supplemental Figure 3A). In contrast, neither heterozygous nor wild-type mice had proteinuria even after 8 weeks. Importantly, rapamycin treatment completely eliminated the incidence of proteinuria in PcKOTsc1 mice (Figure 3, A and B).

Transmission EM (TEM) analyses revealed an effacement of podocytes, as well as mild thickening and irregular shape of the GBM in 4 week-old PcKOTsc 1 mice (Figure 3C). At 8 weeks, no podocyte foot processes could be identified (Figure 3C), and local loss of the fenestrations was observed (data not shown) in PcKOTsc1 mice. As expected, rapamycin treatment prevented all these pathological changes in PcKOTsc1 mice, indicating that mTORC1 activation in podocytes causes cell-autonomous phenotypic changes and dysfunction that lead to malfunction of filtration barrier. Strikingly, scanning EM revealed that mTORC1 activation in podocytes disrupted the normal architecture of foot processes with enlarged podocyte body (Figure 3D and Supplemental Figure 2C).

In both type 1 and type $2 \mathrm{DN}$, the number and density of podocytes are reduced, and the decreased number of podocytes per glomerulus is the strongest predictor of progression of $\mathrm{DN}(2,3$, $28,29)$. To investigate podocyte number in PcKOTsc1 mice, we determined average numbers of podocytes per glomerular tuft area by counting WT1-positive podocytes in PcKOTsc1 mice at various ages (Figure $3 \mathrm{E}$ ). Indeed, the number of podocytes in 3- and 4-week-old PcKOTsc1 mice but not those in 1- to 2-weekold PcKOTsc1 mice was significantly decreased compared with those in wild-type mice. Furthermore, rapamycin treatment for 2 weeks prevented podocyte loss, indicating that mTORC1 activation causes loss of podocytes. Interestingly, these results also suggest that the podocyte loss may not be the sole reason for the initial proteinuria in PcKOTsc1 mice, because 2-week-old PcKOTsc1 mice exhibited proteinuria before apparent podocyte loss.

Given the fact that mTORC1 activation in podocytes induces autonomous podocyte injury and proteinuria, our data support the idea that diabetes-induced mTORC1 activation in podocytes may have a direct role in podocyte injury and proteinuria, thereby contributing to the progression of DN.

mTORC1-dependent podocyte injury and dysfunction are reversible. Clinical experience suggests that tight control of blood glucose levels and/or the proper calorie restriction ameliorate proteinuria in early DN (30). Therefore, we wanted to determine whether mTORC1-dependent podocyte injury is a reversible phenotypic change. To this end, we started rapamycin treatment from 4 weeks age in PcKOTsc1 mice whose podocytes were already injured (Figure 3). Surprisingly, after only 2 weeks of treatment, the massive proteinuria observed at 4 weeks was largely diminished and finally disappeared at 10 weeks age ( 6 weeks treatment) in PcKOTsc1 mice (Figure 4, A and B). Histological and TEM analyses of glomeruli revealed that the eosin-positive compartments were cleared in the mesangial region (Figure 4C) and that foot process formation was significantly restored, although some irregular shape of the GBM still remained (Figure 4D). Scanning EM studies revealed that podocyte foot processes were regenerated around the podocyte body after 2 weeks of rapamycin treatment (Figure 4E). Although we observed different stages of glomeruli in which foot processes 
A
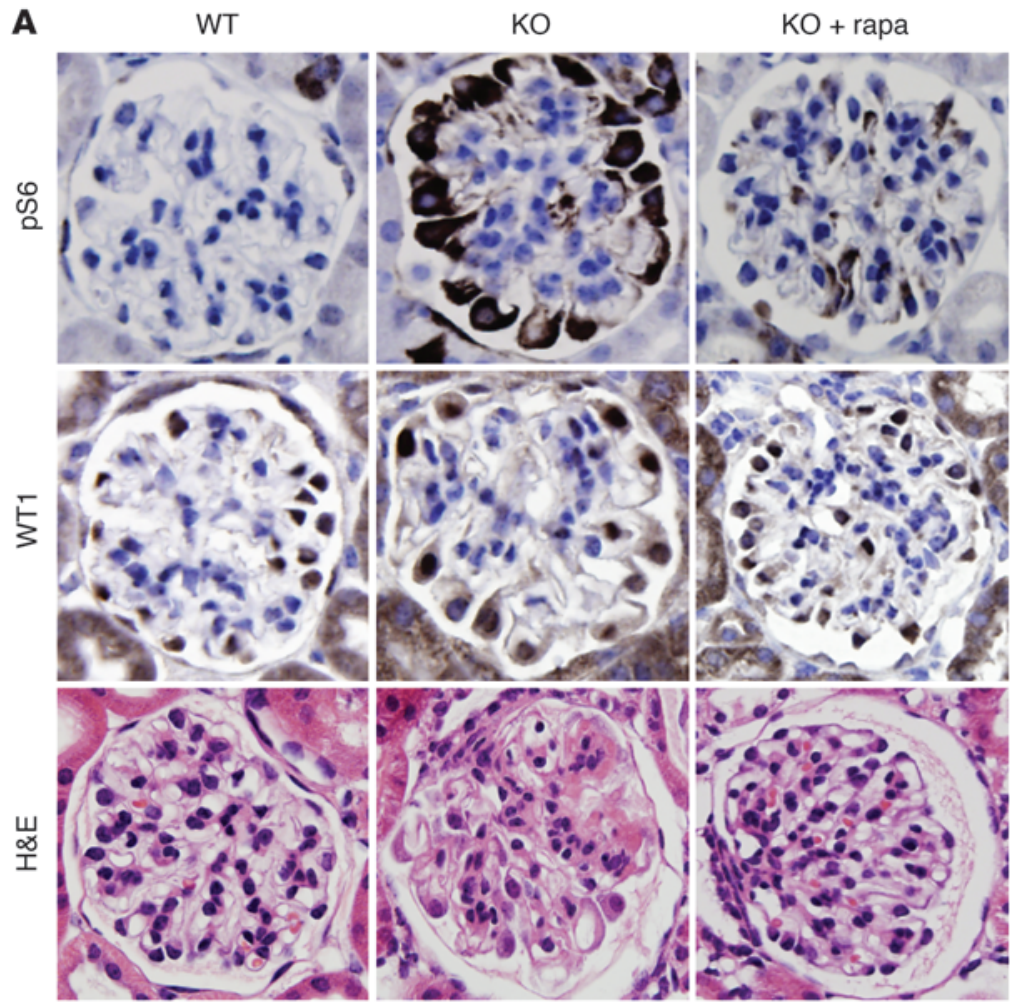

$(3)$
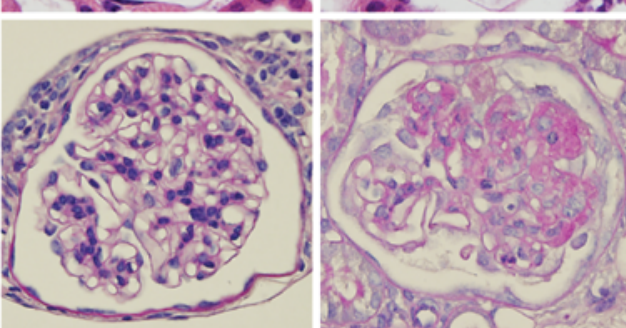

and...5
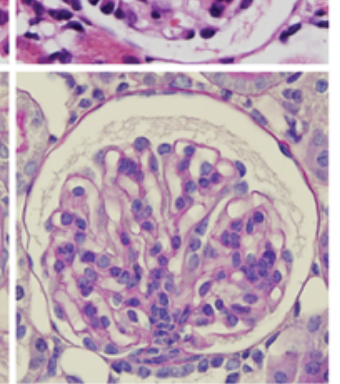

D
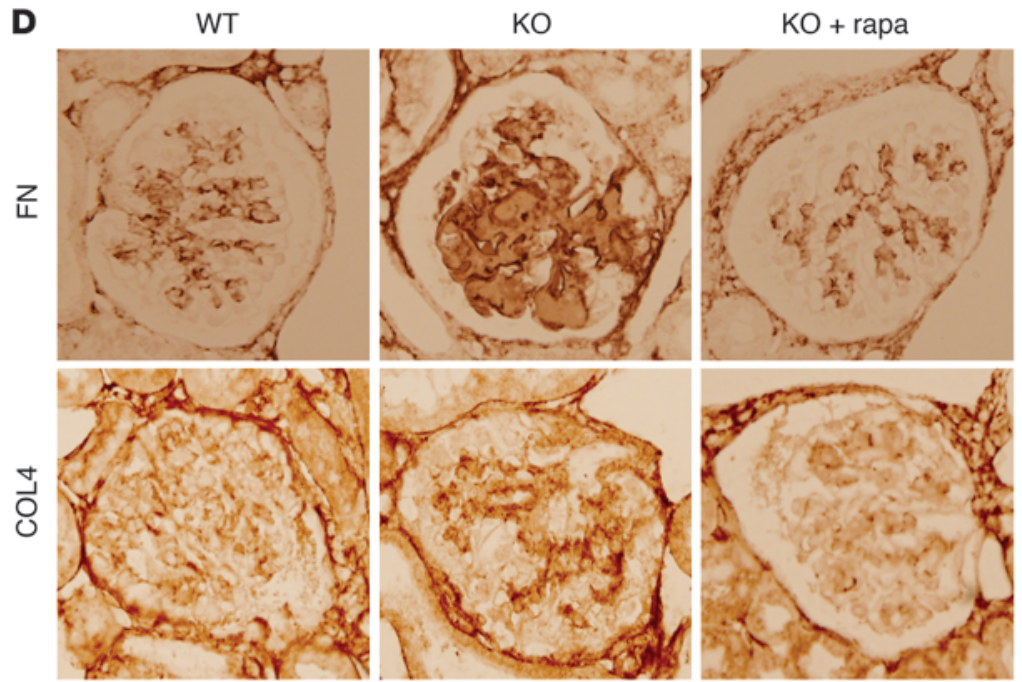
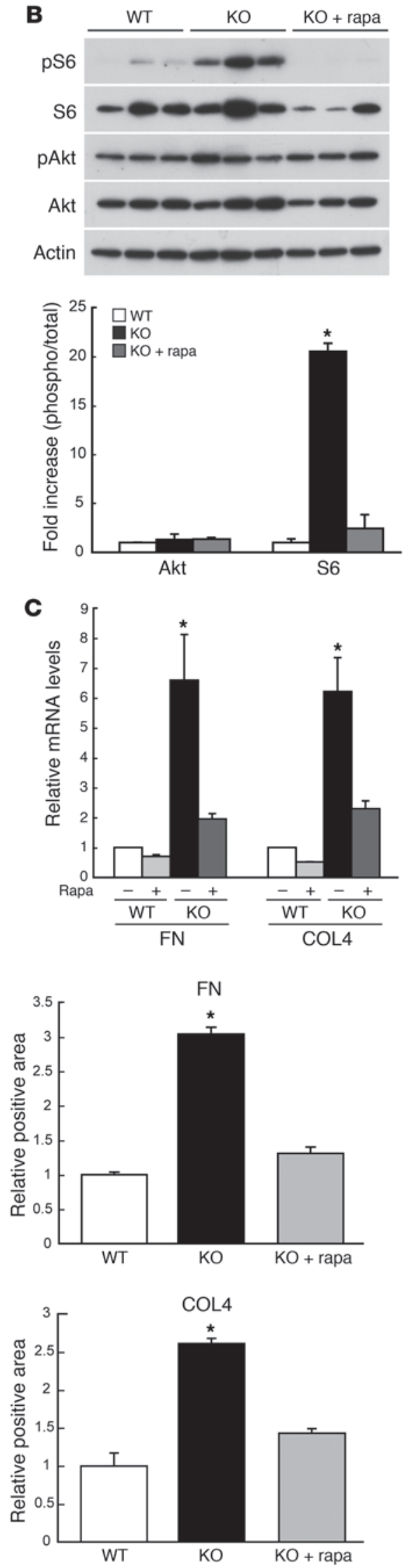


\section{Figure 2}

Characterization of PcKOTsc1 mice. (A) Enhanced S6 phosphorylation, podocyte hypertrophy, and mesangial expansion in PcKOTsc1 glomeruli. Renal tissues from 4-week-old mice of the indicated genotypes were stained with phospho-S6, WT1, H\&E, and PAS as indicated. Representative glomeruli from wild-type, PcKOTsc1 (KO), and rapamycin-treated PcKOTsc1 (KO+rapa) are shown. Rapamycin treatment ( $1 \mathrm{mg} / \mathrm{kg}$, i.p., 3 times/wk) was performed from 2 to 4 weeks of age. (B) S6 but not Akt phosphorylation was enhanced in PcKOTsc1 glomeruli. Levels of phospho-S6, S6, phospho-Akt (Ser473), and Akt in glomeruli from mice of the indicated genotypes were determined by Western blot. The levels of phosphorylation of each protein were quantified. Data are expressed as fold increase in the ratio of phosphoprotein to total protein. ${ }^{*} P<0.001$ versus other groups; mean \pm SEM, $n=3$. (C) Enhanced matrix protein mRNAs in PcKOTsc1 glomeruli. The expression levels of fibronectin (FN) and type IV collagen (COL4) mRNAs in the indicated mouse glomeruli were determined by quantitative RT-PCR. Data were normalized to Hprt1. ${ }^{*} P<0.001$ versus other groups; mean \pm SEM, $n=7$. (D) Enhanced deposition of the matrix proteins in PcKOTsc1 glomeruli. Representative glomerular images of staining for fibronectin and type IV collagen in the indicated animals are shown. The ratio of positive staining area to glomerular area in the indicated animals was determined (10 glomeruli/mouse, 3 mice/group). ${ }^{*} P<0.001$ versus other groups, mean \pm SEM. Original magnification, $\times 400(\mathbf{A}$ and $\mathbf{D})$.

were regenerating in the same kidney, it appeared that a single major process sprouted from the podocyte cell body at the beginning, and foot processes developed from this structure (Figure 4E). These results indicate that mTORC1-dependent podocyte injury and the associated pathological phenotypes are reversible upon inactivation of mTORC1 by rapamycin and lowering mTORC1 activity may induce podocyte replenishment. Importantly, however, rapamycin treatment failed to rescue the phenotypes of 8-week-old PcKOTsc1 mice (data not shown), suggesting that once severe podocyte damage had occurred (Figure $3 \mathrm{C}$ ), such as a severe loss of podocytes with sclerotic glomeruli, these changes might not be rescued with rapamycin treatment. Taken together, the results indicate that reduction of mTORC1 activity may rescue both the decrease in podocyte numbers and the dysfunction of filtration barrier when applied prior to a certain threshold. This is consistent with the observations that patients with DN having microalbuminuria can be effectively treated, but overt proteinuria is often refractory to intensive therapies $(30,31)$.

High mTORC1 activation in podocytes of adult mice also leads to glomerular sclerosis. PcKOTsc1 mice develop glomerulosclerosis and die due to renal failure by 14 weeks after birth (Figure 5A). The causes of early death by 6 weeks may include acute hypovolemic shock due to loss of plasma proteins. We observed massive ascites in these PcKOTsc1 mice (Supplemental Figure 3B). The levels of serum creatinine concentration but not glutamic pyruvic transaminase (sGPT) activity were significantly elevated above the normal reference range in 8-week-old PcKOTsc1 mice (Supplemental Figure 4, A and B) (32). To examine the possibility of strain or genetic background effects on survival and renal phenotype, we also transferred these alleles to the C57BL/6 strain. Although survival was slightly improved for PcKOTsc1 mice in C57BL/6 (Figure $5 \mathrm{~A}$, orange line), they developed proteinuria and glomerulosclerosis at a similar rate (Supplemental Figure 5, A-C), and all died by 15 weeks of age. Since the glomeruli in young mice are still developing, it is possible that mis-coordination of growth or develop- ment between the podocytes and the other glomerular compartments could be a reason for the phenotypic changes in podocytes in the PcKOTsc 1 mice. Moreover, DN normally develops in adults with diabetes. To test whether podocyte mTORC1 activation in adult mice also causes podocyte injury, we treated PcKOTsc1 mice with rapamycin until 15 weeks of age; withdrew the treatment; and monitored proteinuria, histological changes of glomeruli, and survival. Interestingly, these mice rapidly developed proteinuria within 1 week of withdrawal of rapamycin (Figure 5B). Seven weeks after withdrawal of rapamycin treatment, the eosin- and PAS-positive components were accumulated in the mesangial area, and the formation of a tuft adhesion to Bowman's capsule was marked, indicative of glomerulosclerosis in PcKOTsc1 mice (Figure 5C). Furthermore, the trend of the survival curve of these mice was essentially similar to that of young PcKOTsc1 mice not treated with rapamycin (Figure 5A). These data indicate that mTORC1 activation in podocytes also causes injury and glomerulopathy in developed glomeruli, suggesting a role of mTORC1 activation in the acquired glomerulopathy.

$m$ TORC1 regulates the localization of slit diaphragm proteins. Dysfunction of slit diaphragm or cytoskeletal proteins in podocytes leads to foot process effacement with proteinuria and is followed by podocyte loss as seen in genetic glomerulopathies $(33,34)$. In $\mathrm{DN}$, there are mixed reports regarding slit diaphragm expression of proteins such as nephrin in early diabetic glomeruli, though it seems consistent that nephrin expression is reduced in the later stages of DN, possibly due to the decreased number of podocytes (35-38). Since mTORC1 activation in podocytes causes cell-autonomous morphological changes, we hypothesized that mTORC1 activation may inhibit gene expression of the slit diaphragm protein in podocytes. However, mRNA expression of representative slit diaphragm proteins such as nephrin in 3-week-old PcKOTsc1 mice, which have already developed proteinuria, was enhanced compared with that in control mice (Supplemental Figure 2G). However, immunogold nephrin staining characterized by TEM revealed that nephrin expression at interpodocyte filtration slit areas was largely diminished in PcKOTsc1 mice (Figure 6A). We found that total nephrin expression in glomeruli isolated from 3-week-old PcKOTsc1 mice was maintained at levels similar to those in wild-type mice (Figure 6B), raising the possibility that nephrin is mislocalized in the PcKOTsc1 podocytes. Consistent with this hypothesis, confocal microscopic analyses revealed that nephrin was predominantly expressed in cytoplasm, with little found on the plasma membrane in the podocytes of PcKOTsc1 mice (Figure 6C). Furthermore, nephrin failed to colocalize well with synaptopodin, which is abundant in the vicinity of podocyte membranes in PcKOTsc1 mice. Importantly, nephrin was seen on the plasma membrane and colocalized with synaptopodin in PcKOTsc1 mice treated with rapamycin (from 2 to 3 weeks of age). Together these data suggest that abnormal mTORC1 activation results in mislocalization of nephrin, thereby potentially disrupting the integrity of the slit diaphragm and contributing to the effacement of foot processes and the genesis of proteinuria. We found that podocin was also expressed in cytoplasm in PcKOTsc1 mice (data not shown); however, Neph1 was properly membrane localized, suggesting that mTORC1 activation leads to mislocalization of the specific slit diaphragm proteins (Supplemental Figure 6A).

To investigate whether this regulation between MTORC1 and nephrin could be observed in vitro, we examined the localization of nephrin in COS7 cells, which normally do not express 

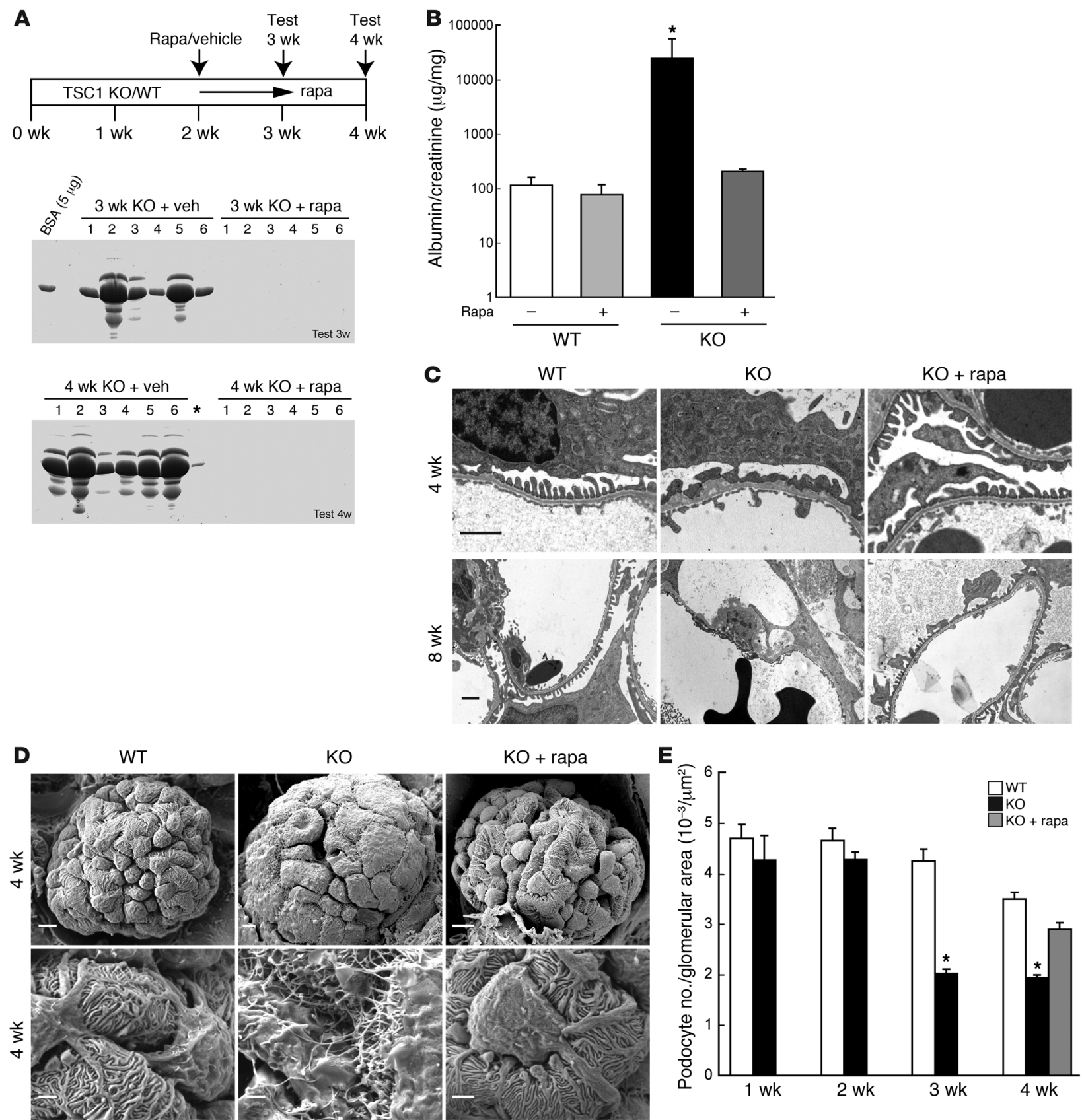

Figure 3

PcKOTsc1 mice show proteinuria and podocyte loss. (A) Rapamycin treatment prevents proteinuria in PcKOTsc1 mice. Scheme of administration of rapamycin is shown above. Urine $(1 \mu \mathrm{l})$ from mice of the indicated genotypes was subjected to SDS-PAGE with Coomassie blue staining ( $n=6$ each group). veh, vehicle. Asterisk indicates a leak of sample from lane 6. (B) Urinary albumin/creatinine ratio is shown. Urinary albumin and creatinine concentrations in 4-week-old mice were determined by ELISA. ${ }^{*} P<0.001$ versus other groups, mean \pm SEM, $n=6$. Note logarithmic scale for the $y$ axis. Rapamycin treatment was performed from 2 weeks of age as indicated in Figure 2A. (C) TEM analyses reveal abnormal foot process and GBM in PcKOTsc1 and wild-type mice. Representative TEM images of the indicated animals (3 mice/group) from 4 and 8 weeks of age are shown. Rapamycin treatment was as in Figure 2A. Original magnification, $\times 13,500$ (top row), $\times 7,900$ (bottom row). Scale bars: 1 um. (D) Scanning EM analyses show abnormal podocyte in PcKOTsc1 mice, which was prevented by rapamycin treatment. Rapamycin treatment was as in Figure 2A. Original magnification, $\times 2,000$. Scale bars: $5 \mu \mathrm{m}$ (top row); $1.25 \mu \mathrm{m}$ (bottom row). (E) Podocyte loss in PcKOTsc1 mice. The ratio (the number of WT1-positive cells/glomerular tuft area [ $\left.\mu \mathrm{m}^{2}\right]$ ) was determined in 15 30 glomeruli from the indicated animals. ${ }^{\star} P<0.001$ versus wild-type and/or KO with rapamycin treatment, mean $\pm \mathrm{SEM}, n=3-5$ mice. 


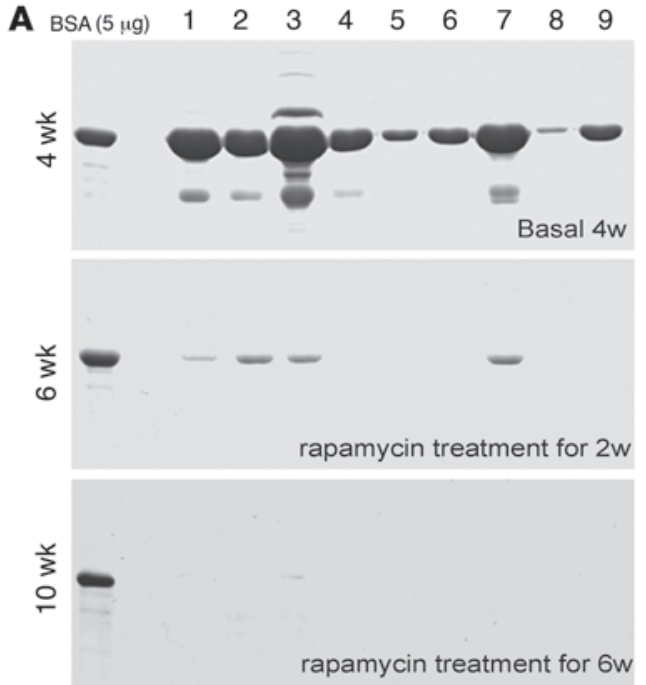

10 wk KO

C
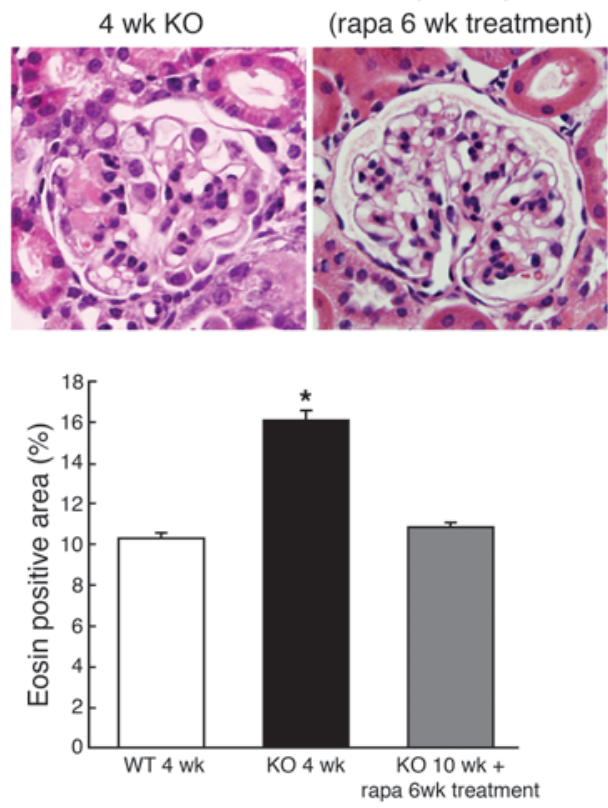

B

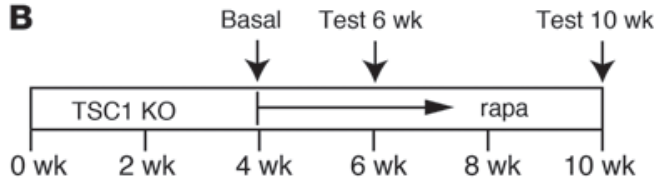

$0 w k \quad 2 w k \quad 4 w k \quad 6 w k \quad 8 w k \quad 10 w k$

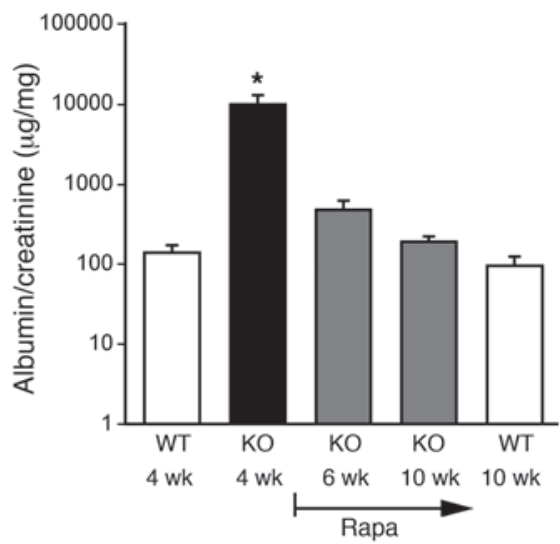

D
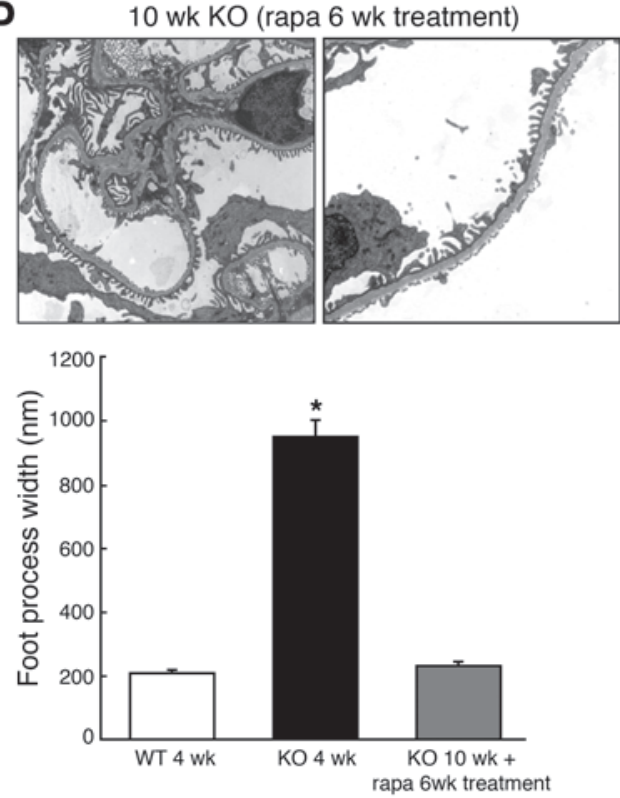

E

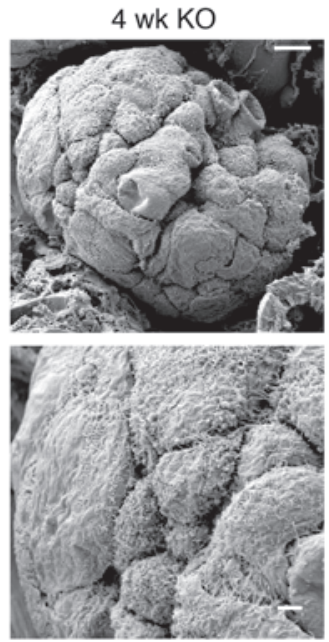

6 wk KO + rapa 2 wk treatment

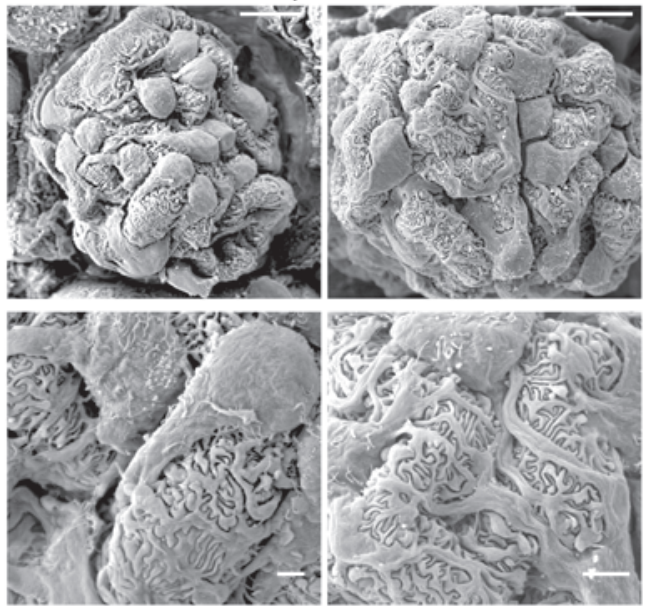

Figure 4

Rapamycin reverses established phenotypes in PcKOTsc1 mice. (A and $\mathbf{B}$ ) Rapamycin treatment ameliorated the established proteinuria in PcKOTsc1 mice. Proteinuriapositive 4-week-old PcKOTsc1 mice $(n=9)$ were treated with rapamycin for 2 and 6 weeks. The levels of urinary protein from 9 mice were tested at the indicated time points and visualized by Coomassie staining $(n=9)(\mathbf{A})$, and the ratio of albumin to creatinine concentration is shown $(\mathrm{B}) .{ }^{*} P<0.001$ versus other groups, mean \pm SEM, $n=9$; note logarithmic scale for $y$ axis. The ratios for 4- and 10-week-old wild-type mice are also shown. (C) H\&E staining of renal tissue from 4-week-old untreated and 10-week-old treated PcKOTsc1 mice (rapamycin treatment for 6 weeks). Eosin-positive area in glomerulus was measured in 30 glomeruli from 4-weekold wild-type and PcKOTsc1 mice as well as 10-weekold treated PcKOTsc1 mice. ${ }^{*} P<0.001$ versus other groups, no statistical significance between WT 4 weeks and $\mathrm{KO}$ with rapamycin 10 weeks, mean \pm SEM, $n=3 \sim 5$. (D) TEM analyses of 10-weekold PcKOTsc1 mice (rapamycin treatment for 6 weeks). Foot process width at the level of slit diaphragm was measured (20 50 foot processes/ glomerulus, 3 glomeruli/mouse, 3 mice/group). ${ }^{*} P<0.001$ versus other groups, mean \pm SEM. (E) Scanning EM analyses of 6-week-old PcKOTsc1 mice (rapamycin treatment for 2 weeks). Representative glomerulus from 2 different rapamycin-treated PcKOTsc1 mice is shown. Original magnification, $\times 400$ (C), $\times 7,900$ (D), $\times 2,000$ (E). Scale bars: $10 \mu \mathrm{m}$ (top row); $2.5 \mu \mathrm{m}$ (bottom row). 
A Rapa $(0.5 \mathrm{mg} / \mathrm{kg})$

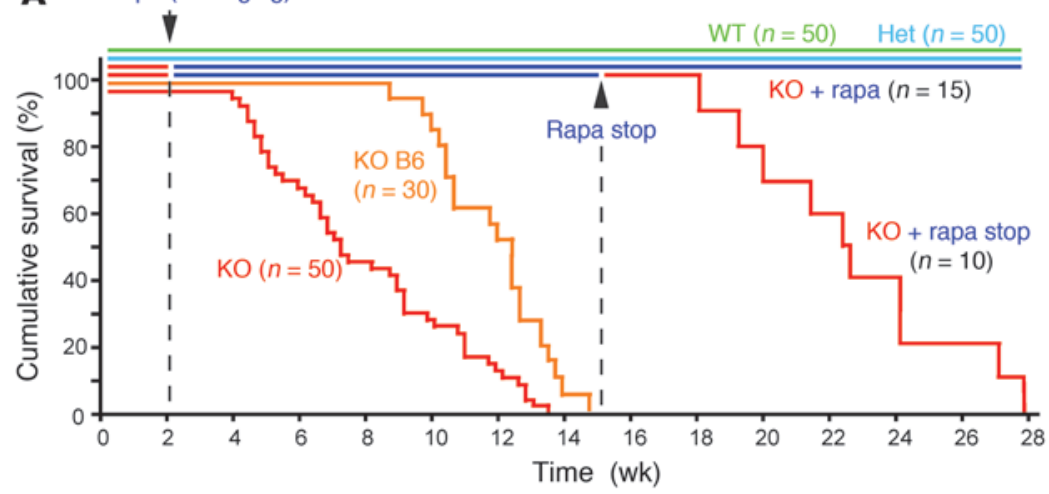

B
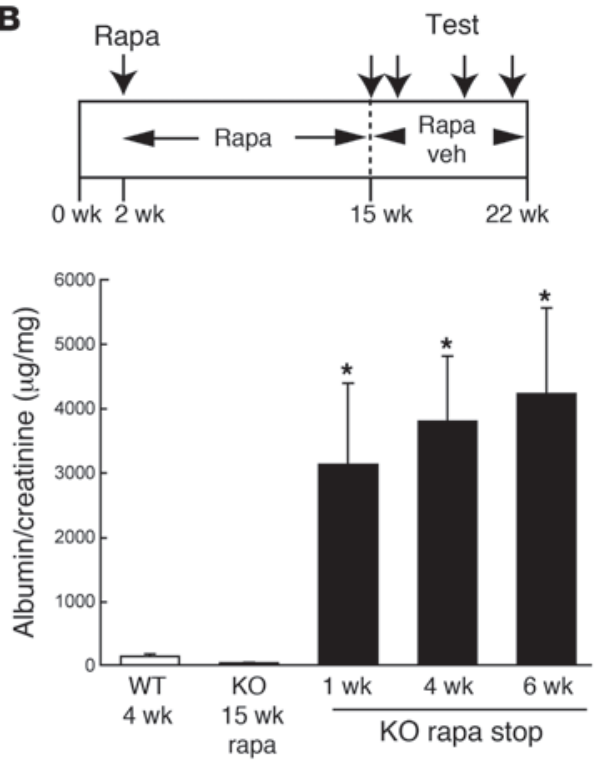

C
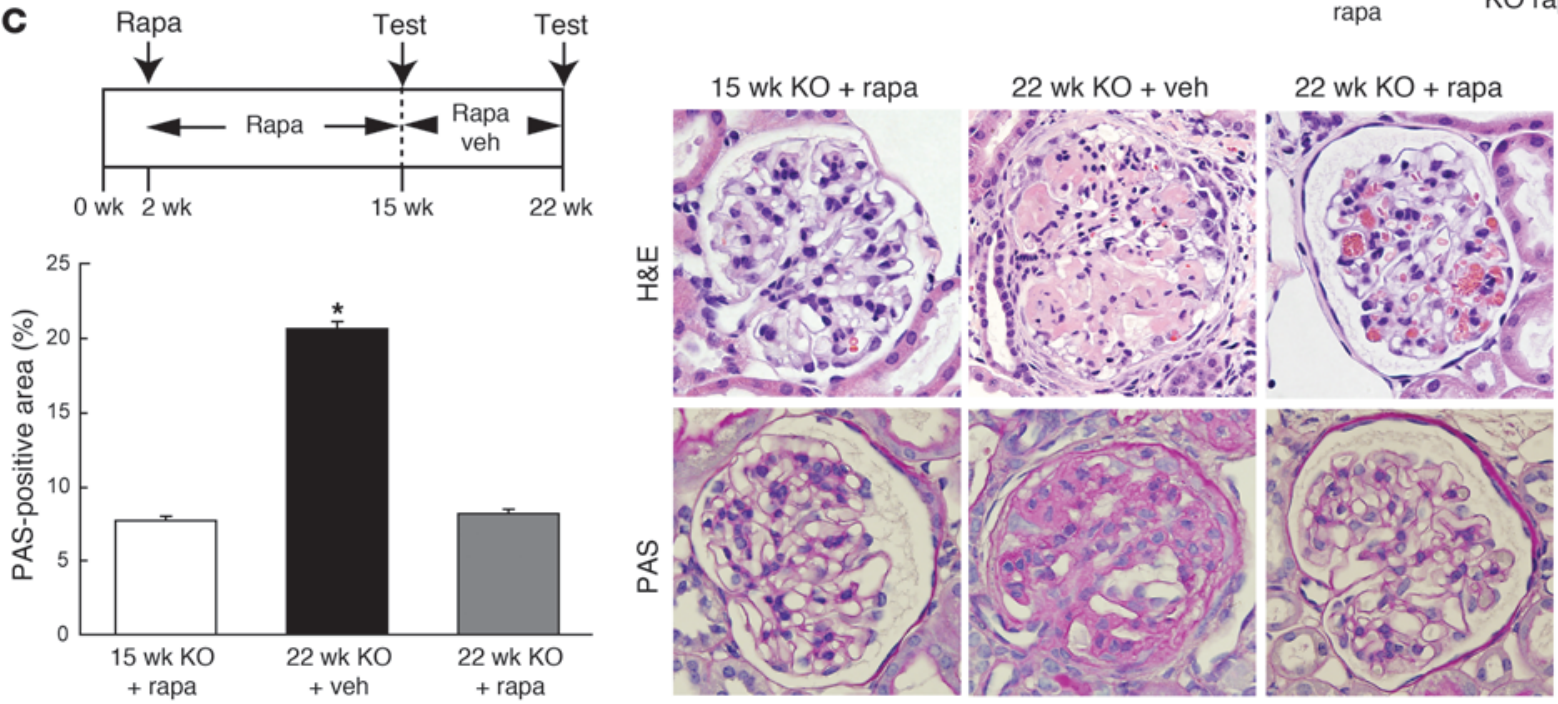

Figure 5

mTORC1 activation in podocytes causes proteinuria and mesangial expansion in adult mice. (A) Rapamycin prevents death in PcKOTsc1 mice. Mice were treated with rapamycin as indicated. Survival curve of the indicated animals is shown. Wild-type, $n=50$; heterozygous (Het), $n=50$; $\mathrm{KO}, n=50$; KO with rapamycin treatment (off-on), $n=15$; KO with rapamycin treatment (off-on-off), $n=10$; KO C57BL/6 (B6) background, $n=30$. (B) mTORC1 activation in podocytes causes proteinuria and mesangial expansion in adult mice. Withdrawal of rapamycin treatment in adult PcKOTsc1 mice led to rapid onset of proteinuria and glomerulopathy. Scheme of administration of rapamycin is shown at top. Urinary albumin concentrations of the indicated animals were determined (WT 4 wk; KO 15 wk [rapamycin treatment from 2 to 15 weeks]; KO 16 wk, $19 \mathrm{wk}$, and $21 \mathrm{wk}$ [off-on-off; $1 \mathrm{wk}, 4 \mathrm{wk}$, and $6 \mathrm{wk}$ after withdrawal of rampamycin treatment]). ${ }^{*} P<0.001$ versus WT and KO $15 \mathrm{wk}$, mean \pm SD, $n=6$. (C) Withdrawal of rapamycin treatment in adult PcKOTsc1 mice led to mesangial expansion. Scheme of administration of rapamycin is shown at top. H\&E and PAS staining of the representative glomeruli are shown. PAS-positive area in glomerulus was measured in 30 glomeruli from the indicated animals. ${ }^{*} P<0.001$ versus other groups, $n=4$. Original magnification, $\times 400$.

podocyte-specific proteins, by ectopically expressing nephrin and Rheb, a potent mTORC1 activator. Transfected nephrin was localized in both plasma membrane and peri-nuclear regions (Figure 7A). As seen in the PcKOTsc1 podocytes, activation of mTORC1 by Rheb resulted in loss of plasma membrane localization of nephrin. Importantly, under these conditions, rapamycin increased nephrin plasma membrane localization. These results suggest that mTORC1 may have a specific role in the regulation of nephrin localization.
To investigate whether nephrin mislocalization is a common pathologic phenotype associated with mTORC1 activation, we examined the pattern of nephrin expression in diabetic animals using confocal microscopy. In nondiabetic $(d b /+)$ mice, a majority of nephrin was linearly expressed on the membrane of podocyte foot process. In contrast, nephrin was diffusely expressed and accumulated in some organelles in the cytoplasm in $d b / d b$ mice podocytes (Figure 7B). Rapamycin treatment diminished cytoplasmic nephrin, and almost all of the nephrin was relocated along with plasma mem- 
A

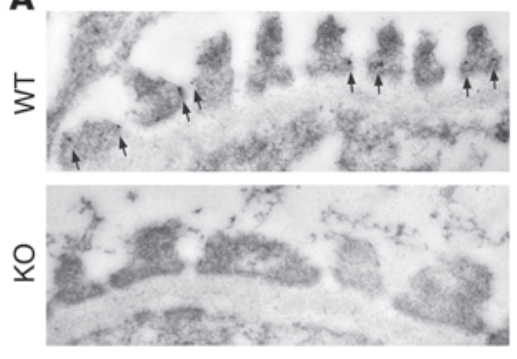

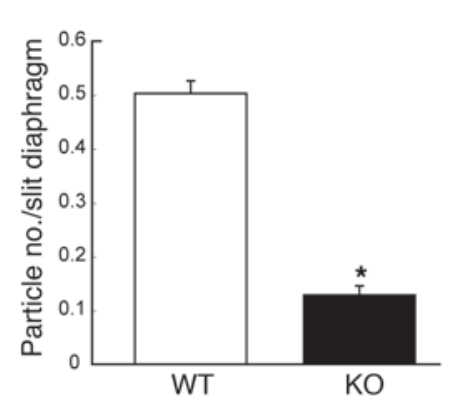

B

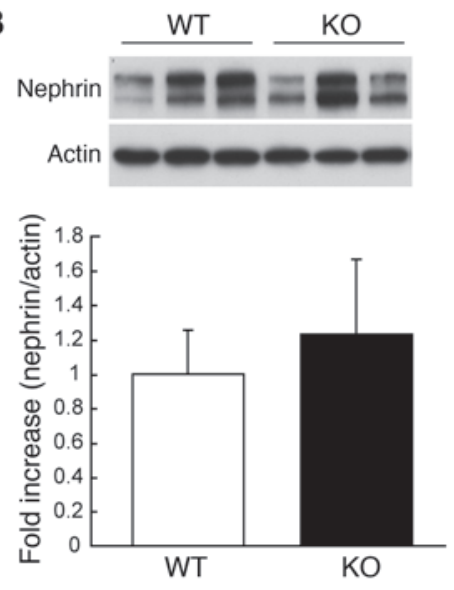

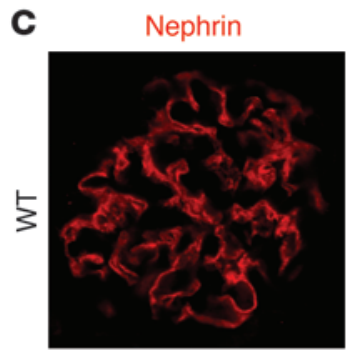
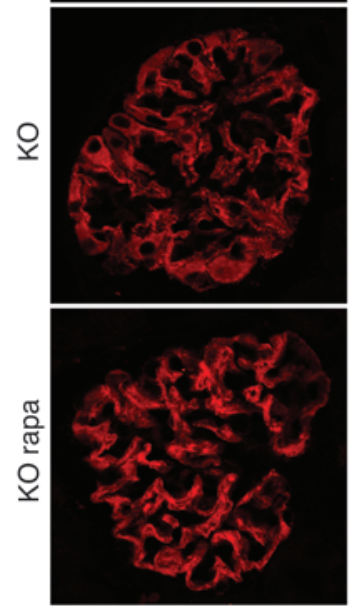

Synaptopodin
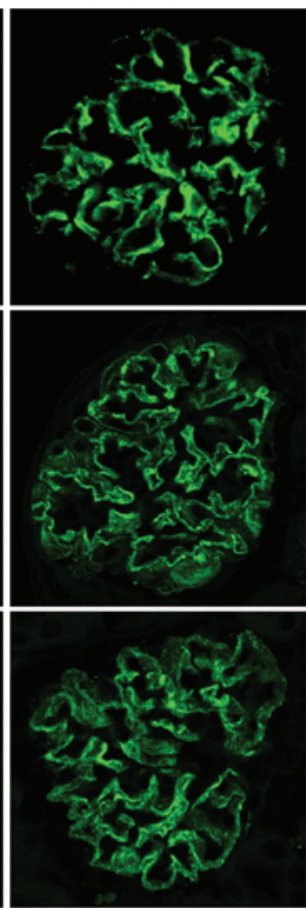

Merge
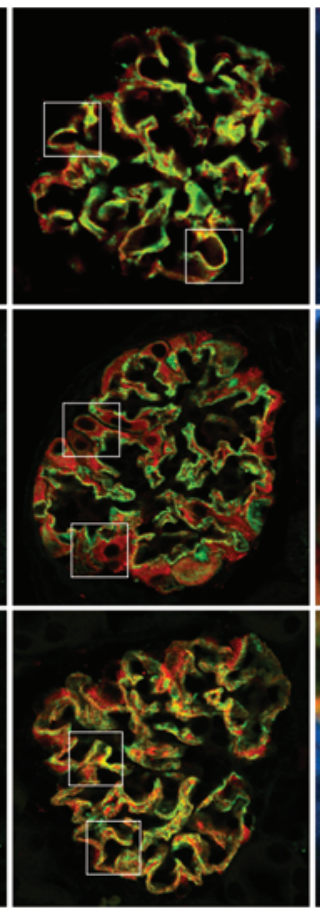

Detail
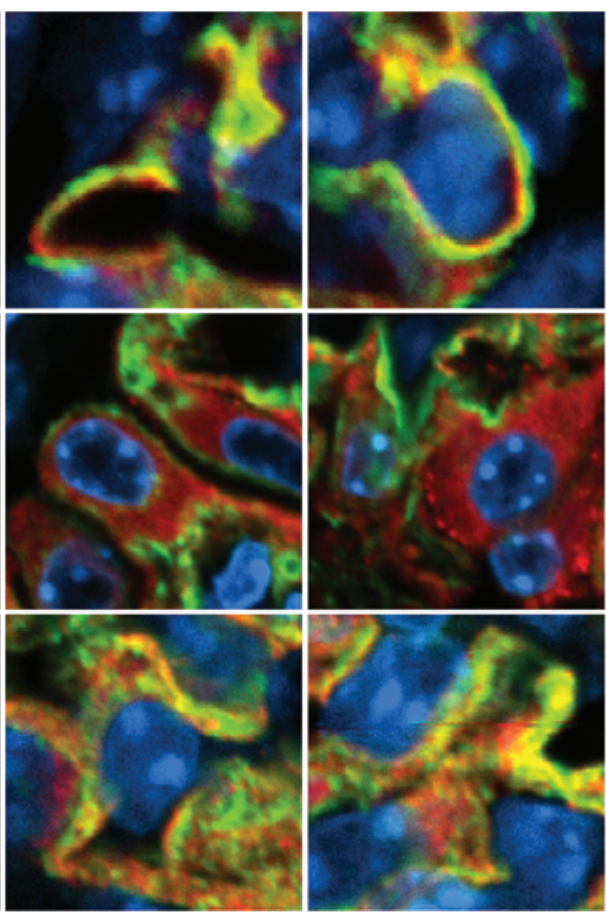

\section{Figure 6}

Hyperactivation of mTORC1 leads to mislocalization of slit diaphragm proteins. (A) Nephrin expression at interpodocyte filtration slit area is diminished in PcKOTsc1 mice. Representative electron micrographs of immunogold nephrin staining in 3-week-old mice are shown. Number of immunogold particles for nephrin at the slit diaphragm was measured in 290 slit diaphragms from 2 wild-type and 170 slit diaphragms from 2 PcKOTsc1 mice. ${ }^{*} P<0.001$ versus wild-type, mean \pm SEM. (B) Nephrin and actin expression in the indicated glomeruli were determined by Western blotting. Levels of nephrin expression in the indicated genotypes were quantified (nephrin/actin). Data are expressed as fold increase. $P=0.67$, mean \pm SEM, $n=3$. (C) Nephrin is mislocalized in PcKOTsc1 podocytes. Confocal microscopic analyses of nephrin and synaptopodin expression in the indicated animals ( 3 weeks old) are shown. Rapamycin treatment was performed for 1 week. Areas indicated by squares in the Merge column are shown at higher magnification in the right two columns. Original magnification, $\times 13,500(\mathbf{A}), \times 400$ (C).

brane in foot processes. Consistent with these observations in the mouse model, human nephrin expression in normal subjects exhibited a liner pattern of expression, whereas it showed a more granular pattern with reduction of its membrane expression in human type 2 DN glomeruli (Figure 7C). Collectively, the above data indicate that proper control of mTORC1 activity in podocytes is important for maintaining intact localization of certain slit diaphragm proteins.
mTORC1 activation converts podocytes to a fibroblastic phenotype and causes podocyte detachment. It has been reported that podocytes display fibroblast-like phenotypic changes and this may cause podocyte loss/detachment in DN (10,39-43). These phenotypes include the expression of desmin and the redistribution of zona occludens-1 (ZO-1). However, the molecular mechanism by which diabetes causes this phenotypic change is not well understood. 
A
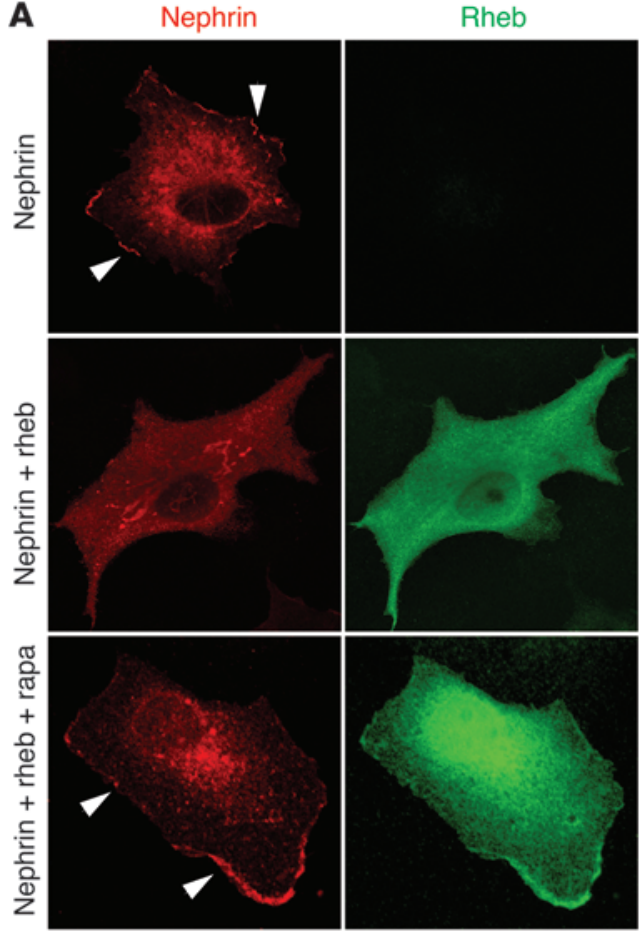

C

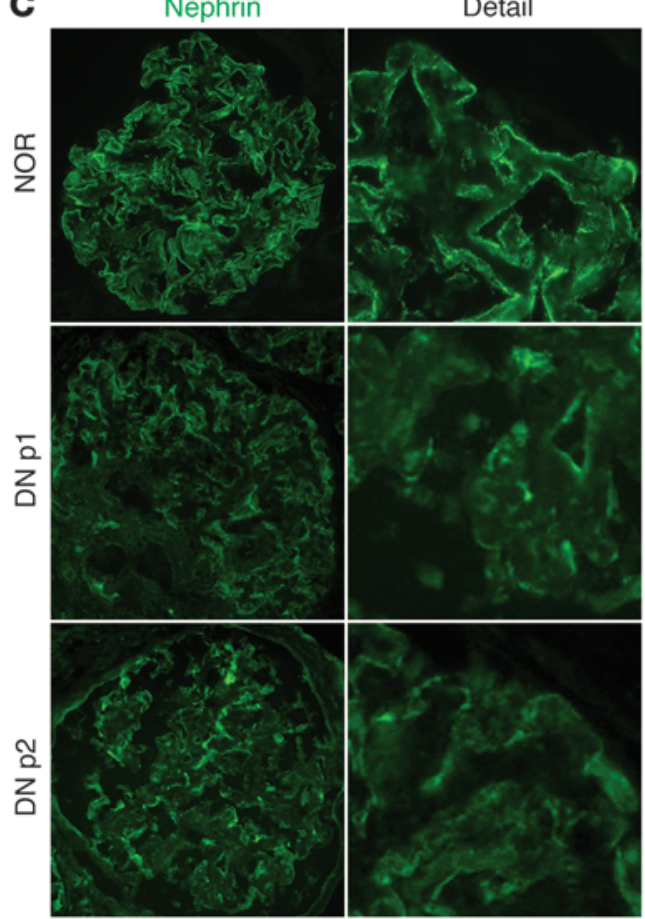

B
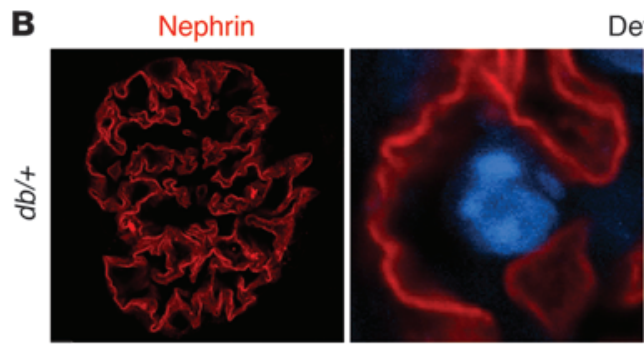

Detail

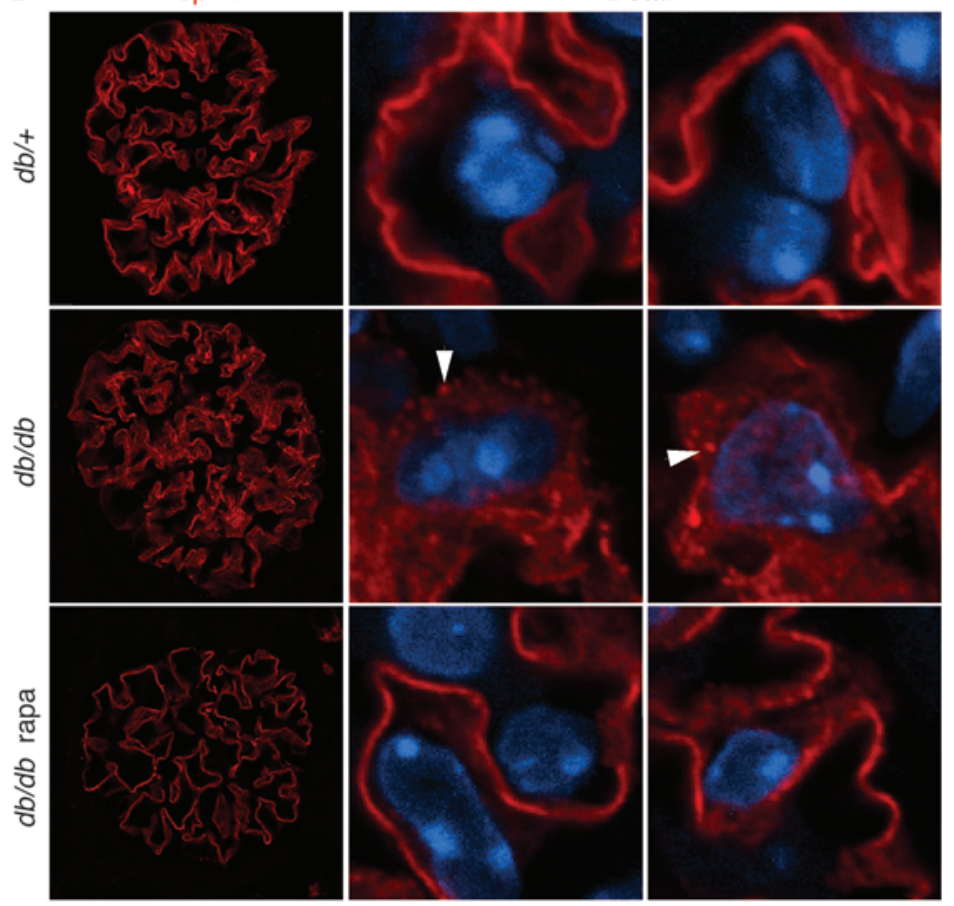

\section{Figure 7}

Mislocalization of nephrin by abnormal mTORC1 activation and diabetes. (A) Membrane localization of nephrin is disrupted by Rheb. Exogenous nephrin expression pattern was analyzed by confocal microscopy. Human nephrin (Myc-Nephrin) was expressed with or without Rheb (HA-Rheb) in COS7 cells. Nephrin and Rheb expression was determined by rabbit polyclonal nephrin and mouse monoclonal HA antibodies, respectively. The arrowheads indicate membrane expression of nephrin. Rapamycin $(20 \mathrm{nM})$ treatment was for 12 hours. (B) Rapamycin treatment restores membrane localization of nephrin in $d b / d b$ mice. The pattern of nephrin expression of the indicated animals ( 25 weeks of age) was monitored by confocal microscopy. Rapamycin treatment was performed from 8 to 25 weeks. The arrowheads indicate the accumulation of nephrin in cytoplasm. (C) Membrane localization of nephrin was reduced in human type 2 DN. Nephrin staining showed a granular pattern expression in cytoplasm with reduced membrane expression (NOR, normal subject; DN p1, DN patient 1). Original magnification, $\times 600(\mathbf{A}), \times 400(B$, and C).

Confocal microscopic analyses showed that ZO-1 expression is redistributed in the cytoplasm (loss of liner expression pattern) and desmin is expressed in the cytoplasm of the WT1-positive cells, indicating that podocytes display a fibroblastic phenotypic change in PcKOTsc1 mice (Figure 8A). Moreover, rapamycin treatment blocked these phenotypic changes. These results suggest that high mTORC1 signaling may be a potential mechanism for fibroblastic phenotypic changes in the podocytes seen in diabetes. In 4-week-old PcKOTsc1 mice, whose podocyte number was significantly decreased (Figure 3E), the levels of desmin expression in the remaining podocytes were further enhanced (Supplemental Figure 8, A-D). This observation suggests that the fibroblast-like phenotypic change in podocytes with desmin expression might be a trigger for podocyte loss. Consistent with this hypothesis, we 
observed cells expressing podocyte-specific mRNAs such as nephrin and podocin in the urine from PcKOTsc1 mice but not those from wild-type mice, suggestive of a detachment of podocytes from the GBM in PcKOTsc1 mice (Figure 8B). However, we did not observe a significant increase in apoptotic cells in PcKOTsc1 mouse glomeruli (data not shown). These observations suggest that mTORC1 activation may induce podocyte loss mainly due to detachment along with epithelial-mesenchymal transition-like (EMT-like) phenotypic changes.

ER stress is an essential factor for podocyte loss in PcKOTsc1 mice. It has been postulated that ER stress is enhanced in tissues such as pancreatic $\beta$ cells as well as renal tubular and glomerular cells under diabetic conditions $(44,45)$. However, the role of diabetes-induced ER stress in podocytes remains unclear. We found that GRP78, which is induced during ER stress, was expressed at higher levels in the podocytes of PcKOTsc1 mice. The accumulation of GRP78 in PcKOTsc 1 podocytes was significantly reduced by rapamycin treatment, suggestive of the elevated ER stress being induced by high mTORC1 activity (Figure 8C). Proper protein post-translational modifications such as glycosylation and oxidation in the ER are essential for nephrin to localize at the membrane (46); furthermore, it has been reported that ER stress triggers EMT in thyroid cells (47). To study the role of ER stress in podocyte phenotypic changes in PcKOTsc1 mice, we utilized 4-phenyl butyric acid (PBA), a chemical chaperone that has been used to reduce ER stress in the pancreatic $\beta$ cells under diabetic conditions (48). We found that PBA treatment effectively reduced the accumulation of GRP78 (Figure 8D) in the podocytes and partially but significantly prevented the loss of podocytes in 8-week-old PcKOTsc1 mice (Figure 8, D and E). Furthermore, loss of nephrin and synaptopodin expression was moderately restored in PBA-treated 8-weekold PcKOTsc1 mice (Figure 8D). These data indicate that high mTORC1-induced ER stress causes podocyte loss in PcKOTsc1 mice. In agreement with this hypothesis, reduction of ER stress with PBA treatment in PcKOTsc1 mice significantly attenuated desmin expression in podocytes (Supplemental Figure 8, A-D), suggesting that the mTORC1-induced change in podocytes to a fibroblastic phenotype was at least in part due to ER stress. It is worth noting that PBA treatment has little effect on S6 phosphorylation in PcKOTsc1 mouse podocytes (Supplemental Figure 8, B, $\mathrm{C}$, and $\mathrm{E}$ ), indicating that unlike rapamycin, $\mathrm{PBA}$ only attenuates the mTORC1-induced ER stress pathway. Intriguingly, despite the protective role of PBA in the fibroblastic phenotypic change and loss of podocytes in PcKOTsc1 mice, it had little effect on proteinuria in the course of the treatment in PcKOTsc1 mice (Figure 8F). Consistent with this observation, PBA treatment failed to restore nephrin localization to the plasma membrane (Supplemental Figure $8 \mathrm{~F}$ ). These data indicate that ER stress induced by mTORC1 activation may contribute to podocyte damage in this model, but does not explain nephrin mislocalization.

Reduction of $m$ TORC1 complex in the podocytes protects the development of $D N$. The question that logically arises from the above observations is whether inhibition of MTORC1 activation in podocytes alone would be sufficient to prevent DN. To test this hypothesis, we generated podocyte-specific knockout of RAPTOR, an essential component of mTORC1 (49). Conventional Raptor-KO mice display early embryonic lethality (50); however, podocyte-specific Raptor-KO mice were born at normal Mendelian ratios and grew normally (data not shown). Interestingly, podocyte-specific Raptor$\mathrm{KO}$ mice also display severe proteinuria from an early stage (51), suggesting that basal mTORC1 activity is required for maintaining podocyte function. Therefore, we generated podocyte-specific Raptor-heterozygous mice on a BLKS $(d b /+)$ background to create type 2 diabetic animals whose mTORC1 complex is reduced only in podocytes (DM Raptor ${ }^{+-}$). DM Raptor ${ }^{+/-}$mice developed obesity and diabetes similar to $d b / d b$ mice (DM). The levels of blood glucose and urine volume were significantly increased in both DM Raptor $^{+/-}$and DM mice compared with those in control mice $(d b /+)$ (Figure 9, A and B). However, at 40 weeks of age, the accumulation of PAS-positive components within the mesangial area observed in DM mice was significantly lower in DM Raptor ${ }^{+/-}$mice (Figure 9, C and D, and Supplemental Figure 8A), though the glomerular area in DM Raptor ${ }^{+/-}$mice was not significantly reduced (Figure 9E). Importantly, nephrin was properly expressed along the membrane of the podocytes and nicely colocalized with synaptopodin in DM Raptor ${ }^{+/-}$mice (Figure 9F). TEM study revealed that DM Raptor $^{+/-}$mice showed a resistance to foot process effacement and GBM thickening (Supplemental Figure 8B). Consistent with these observations, DM Raptor ${ }^{+/}$mice showed less proteinuria compared with DM mice (Figure 9G and Supplemental Figure 8C). Together our data indicate that mTORC1 activation in podocytes under diabetic conditions is a critical factor for the development of DN.

\section{Discussion}

The results presented in this study demonstrate the critical role of site-specific mTORC1 activation in the podocyte in the development of DN. Improper mTORC1 activation in podocytes under diabetic conditions is crucial for podocyte injury and the genesis of proteinuria and may also cause dysfunction of other glomerular cells.

We found that mTORC1 activation was implicated in multiple molecular events in podocytes, including ER stress with a fibroblastic phenotypic change and the mislocalization of slit diaphragm and tight junction proteins. Reduction of mTORC1 activity is important for both lowering ER stress and maintaining intact localization of the slit diaphragm proteins. Interestingly, the reduction of ER stress with PBA, a chemical chaperone, significantly prevented fibroblastic changes in podocytes and their loss; however, it failed to ameliorate mislocalization of slit diaphragm proteins and proteinuria in PcKOTsc1 mice. These data suggest that pathological signaling that leads to proteinuria and podocyte loss may bifurcate downstream of mTORC1 (Supplemental Figure 9). Although it has been postulated that ER stress triggers EMT in thyroid and lung epithelial cells $(47,52)$, and our data also suggest a role for ER stress in fibroblastic phenotypic changes in PcKOTsc1 podocytes, the precise mechanisms by which reduction of ER stress by PBA prevents EMT-like phenotypic changes as well as podocyte loss in PcKOTsc1 mice remain unclear. Besides its chaperone activity, PBA has a weak inhibitory effect on histone deacetylase $(53,54)$. Moreover, phenylacetylglutamine (PAGN), a major metabolite of PBA, functions as an ammonia scavenger and is in clinical use to prevent neuronal cell damage in urea cycle disorders $(55,56)$. It is possible that PBA might exert multiple salutary effects for podocyte survival in PcKOTsc1 glomeruli.

In animal studies as well as clinical reports, rapamycin/sirolimus treatment is reported to show both renoprotective and deteriorative effects on proteinuria and/or renal function $(57,58)$. Especially in renal transplantation, there is a body of evidence indicating that incidence of proteinuria is increased after conversion from calcineurin inhibitor (CNI) to sirolimus-based immunosuppression therapy, although rapamycin shows less nephrotoxicity. Protein- 
A

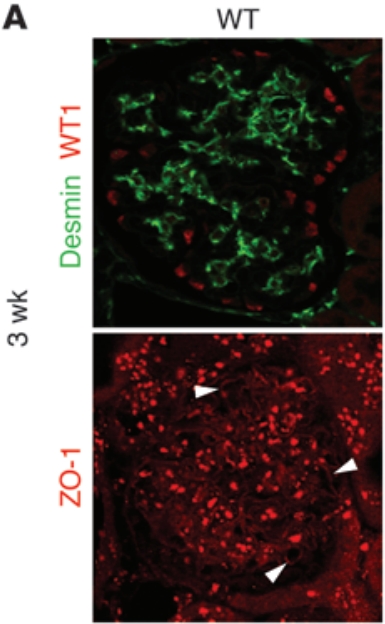

C

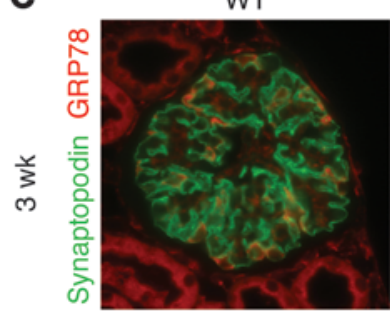

D

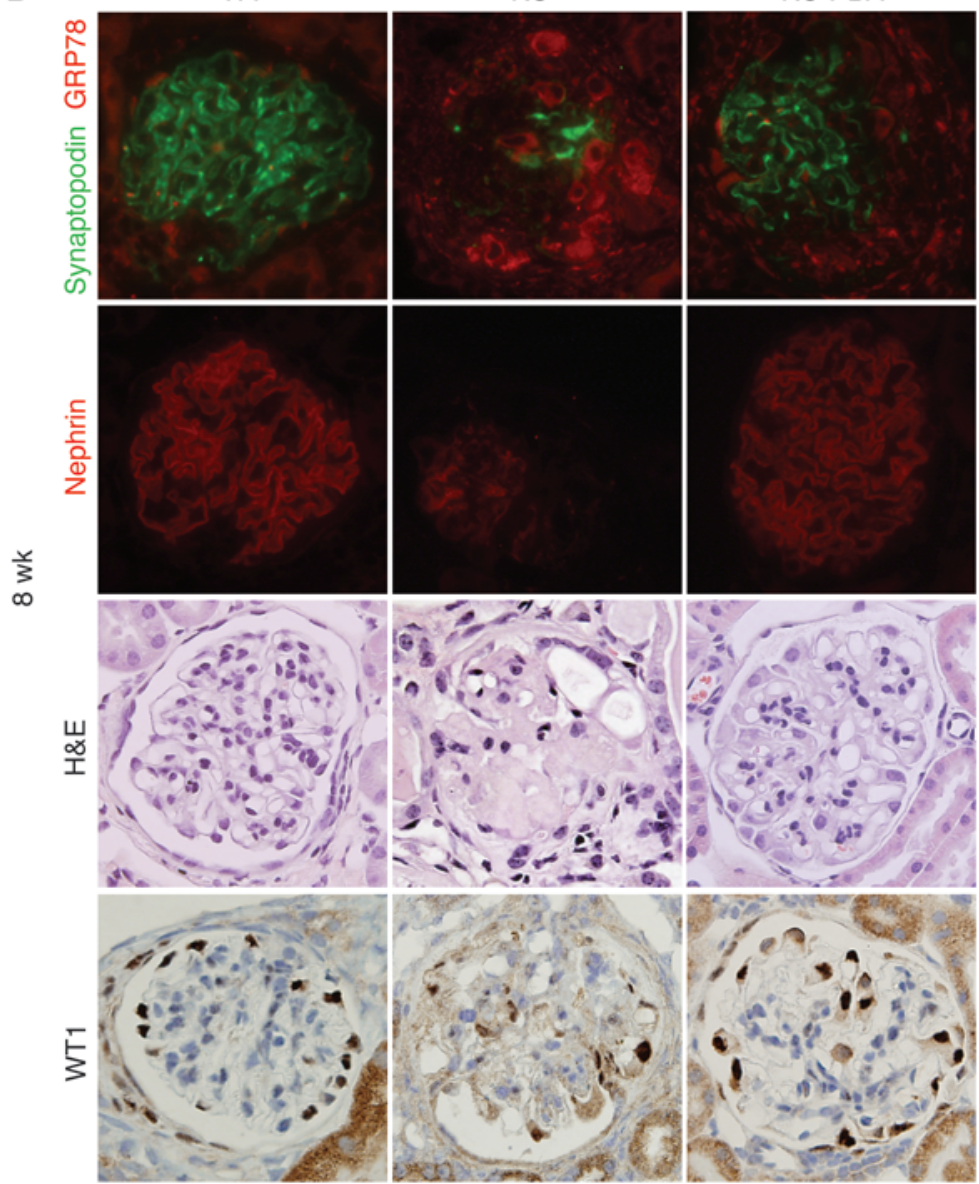

KO rapa

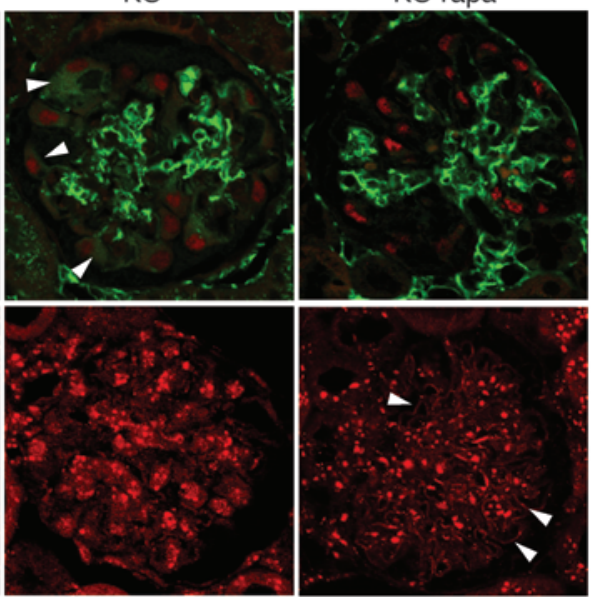

KO

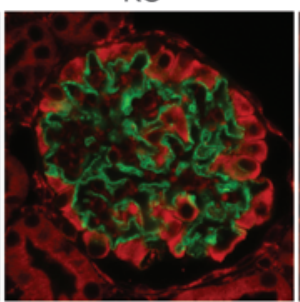

KO

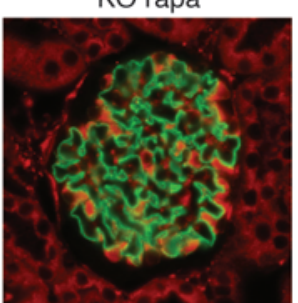

KO PBA
E

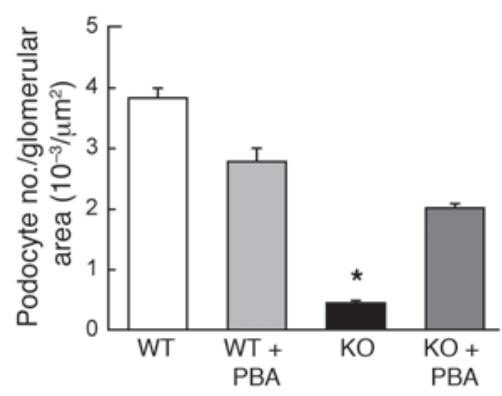

$\mathbf{F}$

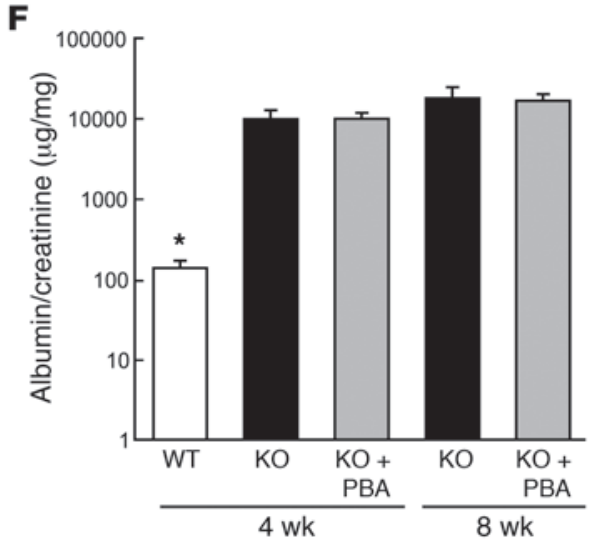




\section{Figure 8}

Hyperactivation of mTORC1 induces ER stress and EMT-like phenotype in podocytes. (A) EMT-like phenotypic changes were induced in PCTSC1KO podocytes. Double staining with desmin and WT1 antibodies was performed in renal tissues from the indicated animals and analyzed by confocal microscopy (top row). Arrowheads indicate desmin expression in the podocytes. Rapamycin treatment was performed for a week. ZO-1 expression was analyzed by confocal microscopy (bottom row). Arrowheads indicate the liner expression pattern of ZO-1. (B) Detection of nephrin and podocin mRNA in PcTSC1KO urinary sediments. Twenty-four-hour urine samples were collected from the indicated animals. RT-PCR was performed using purified mRNA from the sediments. Glomerular mRNA was used as a positive control (p). (C) Accumulation of GRP78 in PcKOTsc1 podocytes (3 weeks of age). Double staining using anti-GRP78 and anti-synaptopodin antibodies in the indicated glomeruli is shown. Rapamycin treatment was performed for 1 week. (D) PBA treatment protects podocyte loss in PcKOTsc1 mice. Staining with GRP78 plus synaptopodin, nephrin, H\&E, and WT1 is shown in the indicated animals ( 8 weeks of age). PBA treatment $(400 \mathrm{mg} / \mathrm{kg} / \mathrm{d}$, i.p.) was performed for 6 weeks. (E) Podocyte number in the indicated glomerular sections from 8-week-old animals was measured. The ratio (number of WT1-positive cells/glomerular tuft area $\left[\mu \mathrm{m}^{2}\right]$ ) was determined in 15 30 glomeruli from the indicated animals as in Figure 3E. ${ }^{*} P<0.001$ versus other groups, mean \pm SEM, $n=4 \sim 8$. (F) Urinary albumin concentrations were measured in the indicated animals. ${ }^{*} P<0.001$ versus other groups; no statistical significance was observed between $\mathrm{KO}$ and $\mathrm{KO}$ with PBA treatment; mean $\pm \mathrm{SEM}$, $n=4 \sim 8$. Original magnification, $\times 400(\mathbf{A}, \mathbf{C}$, and D).

uria observed in renal allograft recipients treated with sirolimus has both glomerular and tubular origins (59). As seen in podocyte-specific Raptor- (51) and insulin receptor-KO (Insr-KO) mouse models (60), it is now evident that the PI3K-mTORC1 function in podocytes is indeed essential for maintaining podocyte function as well as the integrity of the filtration barrier. Therefore, complete inhibition of mTORC1 activity with sirolimus/rapamycin treatment may worsen podocyte function and fail to yield a better clinical outcome. We also observed that prolonged rapamycin treatment occasionally causes atrophy of the renal medulla in mice (data not shown). Given the fact that the levels of rapamycin-sensitive phosphorylated S6 are higher in the tubular region under normal conditions, it is possible that renal tubular epithelial cells require relatively high $\mathrm{mTORC} 1$ activity for their constant turnover, and their dysfunction and/or atrophy by prolonged mTORC1 inhibition may cause tubular proteinuria.

In contrast to that in the tubular region, glomerular mTORC1 activity is kept at a very low level in vivo under normal conditions. The reason why mTORC1 activity is suppressed in the glomerulus is uncertain. However, it is conceivable that activation of mTORC1 in podocytes under diabetic conditions may interfere with the maintenance of the elaborate structure of the highly differentiated podocytes and their functions. It is striking that the podocyte bodies are enlarged and the foot process are diminished in PcKOTsc1 mice in a rapamycin-sensitive manner. Importantly, these podocyte morphological changes are not developmentally programmed, but are dynamically regulated by ongoing mTORC1 activity, as seen in the phenotypes of PcKOTsc1 mice with rapamycin on-off or off-on treatments. Although the molecular mechanisms underling mTORC1-dependent dynamic structural changes in podocytes remain unknown, it is intriguing to speculate that they may share common bases with abnormal dendrite formation by mTORC1 activation (61). Ablation of TSC1 in hippocampal pyramidal neurons or hypothalamic neurons such as proopiomelanocortin (POMC) neurons increases soma size but decreases density of dendritic spines and impairs dendrite projection $(62,63)$. Although evidence is limited, disruption of microtubule formation and actin dysorganization may play a critical role for dendrite as well as podocyte injury under mTORC1 activation.

Our study may also evoke an exiting molecular link between mTORC1 and Notch signaling pathway in podocytes. It has been recently reported that elevated mTOR signaling correlates with enhanced Notch signaling in human breast cancer and angiomyolipoma-derived cells $(64,65)$. More importantly, activation of Notch1 (ICN1) signaling in podocytes plays a crucial role in the development of DN and focal segmental glomerulosclerosis (FSGS) (66). Interestingly, an excess activation of Notch1 signaling under pathological conditions causes dendritic atrophy as well as podocyte injury/loss $(67,68)$. Furthermore, Notch 1 activation induces EMT during cardiac development (69). Given the fact that TGF- $\beta 1$ induces active Notch 1 in a PI3K-independent manner in podocytes, it is likely that mTORC1 may function upstream of Notch1 signaling in the development of podocyte injury (66). Future studies will be required to address how mTORC1 activity links to the molecular events described above.

Our study demonstrates important pathological roles of mTORC1 activation in the podocyte for its dysfunction and the development of DN in mouse models. Although evidence showing a pathological role for the mTORC1 pathway in the development of human DN is still limited, there are considerable phenotypic similarities among PcKOTsc1 mice, diabetic animals, and human $\mathrm{DN}$, including podocyte injury, nephrin mislocalization, cytokine expression, mesangial expansion, and proteinuria $(36,70,71)$.

Although it is necessary to explore the functional significance of the mTORC1 pathway in other renal as well as glomerular cells, our study raises the possibility that rapamycin given at low doses, designed to reduce but not abolish mTORC1 activity in podocytes, may significantly rescue podocyte injury and thereby block the development of DN. Our data also suggest that chemical chaperons such as PBA, an FDA-approved drug for management of urea cycle disorders, may warrant attention as a potential therapy for DN.

\section{Methods}

Reagents. PBA and rapamycin were purchased from Sigma-Aldrich and LC Laboratories, respectively. Nephrin, neph1, and podocin antibodies were described previously $(72,73)$. Guinea pig anti-nephrin antibody (GP-N2, PROGEN Biotechnik) was used for human samples. Phospho-S6 (nos. 4857, 4854, and 2211), S6 (no. 2217), phospho-Akt (Ser473) (no. 4058), and Akt (no. 9272) antibodies were from Cell Signaling Technology. ZO-1 and fibronectin antibodies were from Invitrogen. Type IV collagen antibody was from Millipore. TGF- $\beta$ (sc-7892) and WT1 (sc-192) antibodies were from Santa Cruz Biotechnology Inc. GRP78 antibody was from Abcam. Angiotensin II Receptor Type-2 antibody was from Alomone Labs. HA mAb was from Covance. Synaptopodin, desmin, actin, and HSP90 Abs were from Geneway Research, Dako, Sigma-Aldrich, and BD Biosciences, respectively. Human nephrin and Rheb cDNAs were described previously (72).

Human materials. Human kidney biopsy material was collected after receipt of informed consent from the patients, with the protocol approved by the Scientific-Ethical Committee of the Hospital of Milan (Ospedale S. Carlo Borrome). Frozen kidney sections used for the study were those remaining after completion of diagnosis of type 2 diabetic nephropathy class 1 , according to the classification previously reported (74). Control kidneys were from the unaffected pole of tumor nephrectomies. 

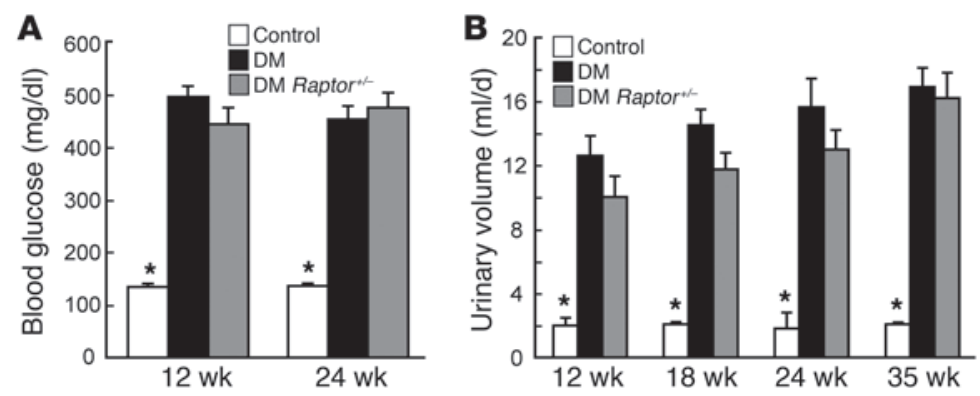

C
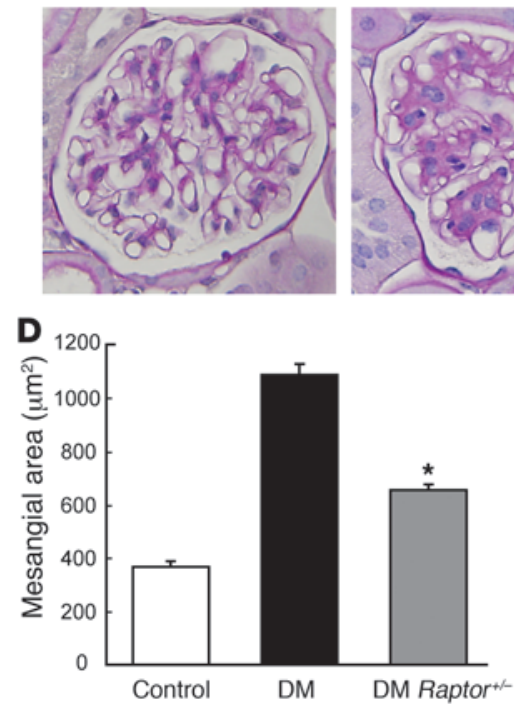

E

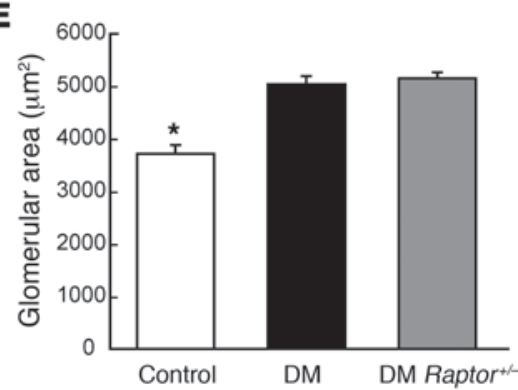

$\mathbf{F}$
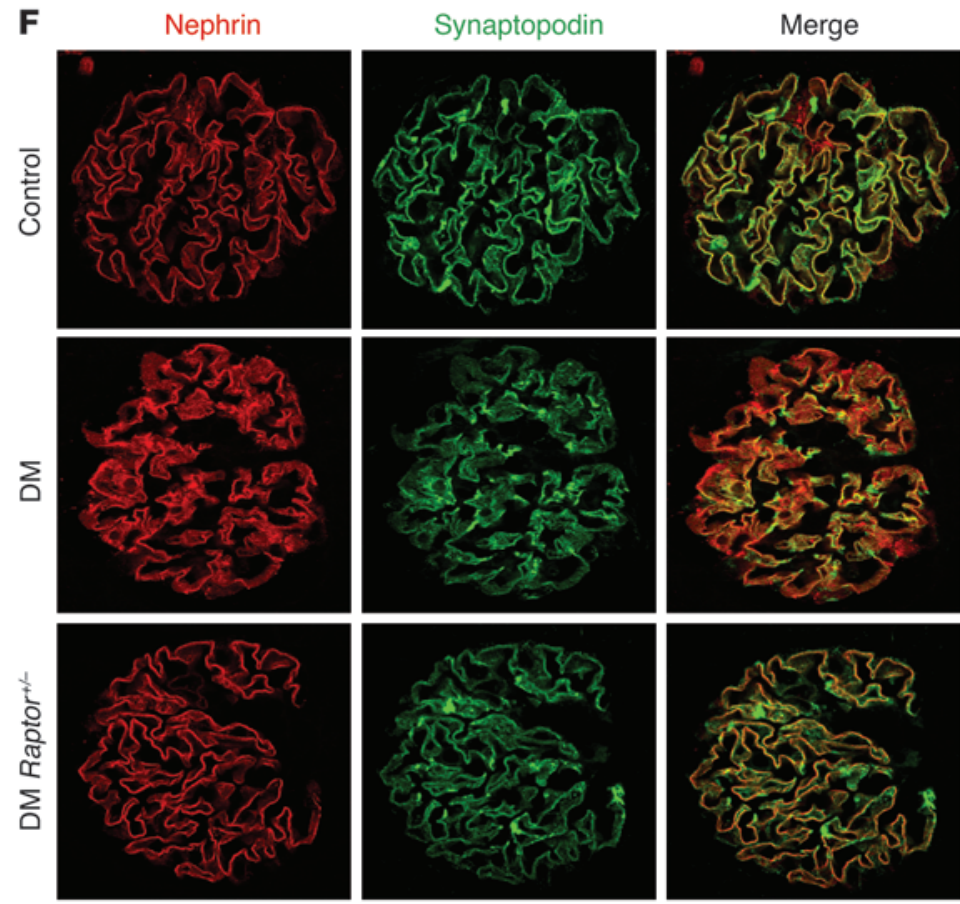
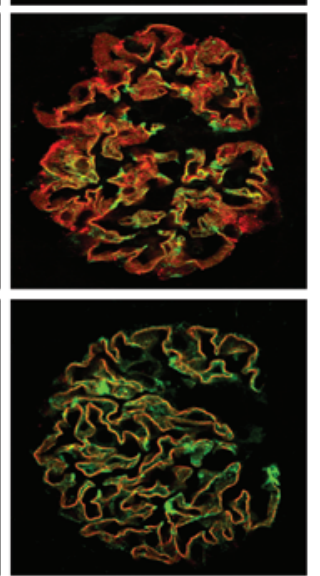

\section{Figure 9}

Podocyte-specific Raptor-heterozygous mice show resistance to the development of DN. (A) Podocyte-specific Raptor-heterozygous $d b / d b$ mice (DM Raptor+/-) develop diabetes to the same extent as control $d b / d b$ mice. Blood glucose levels in the indicated animals are shown. ${ }^{*} P<0.001$ versus DM and DM Raptor ${ }^{+-}$; no statistical significance was observed between DM and DM Raptor $^{+/-}$; mean \pm SEM, $n=6 \sim 8$. (B) Twenty-four-hour urine volume of the indicated animals. Data are expressed as an average of the amount of urine for 3 days. ${ }^{*} P<0.001$ versus DM and DM Raptor+/; no statistical significance was observed between DM and DM Raptor+/-; mean \pm SEM, $n=6 \sim 8$. (C) DM Raptor+/- mice show resistance to the development of mesangial expansion. Representative H\&E and PAS staining of the mice at 40 weeks of age is shown. (D) PAS-positive mesangial area was quantified using ImageJ software. PAS staining was performed in the indicated renal tissues, and PAS-positive mesangial area of 10-20 glomeruli cut at the vascular pole were measured. ${ }^{*} P<0.001$ versus other groups, mean $\pm \mathrm{SEM}, n=6 \sim 8$. (E) DM Raptor+/- mice developed glomerular hypertrophy. Glomerular area was quantified as described in $\mathbf{D}$. ${ }^{*} P<0.001$ versus other groups; no statistical significance was observed between DM and DM Raptor $^{+/-}$; mean \pm SEM, $n=6 \sim 8$. (F) Decreased RAPTOR dosage prevents nephrin mislocalization in DM mice. Confocal microscopic analyses of nephrin and synaptopodin expression in the indicated animals (40 weeks old) are shown. (G) DM Raptor $^{+/-}$mice show resistance to proteinuria. Urinary albumin and creatinine concentrations were measured in 24-hour urine samples from the indicated animals. Albumin/creatinine ratio is shown. ${ }^{*} P<0.01$ versus DM and control, mean \pm SEM, $n=6 \sim 8$. Original magnification, $\times 400(\mathbf{C}$ and F). 
Animals and animal care. To generate mice with Tsc1 deletion specifically in podocytes (PcKOTsc1), we crossed Tsc $1^{\text {fl/l }}$ mice (129S4/SvJae) with Tg (Nphs2 [podocin]-Cre) (C57BL/6J) mice (63). [Tg (Nphs2-Cre), Tsc $\left.1^{f /+}\right] \times\left[T_{s c} 1^{f / f f}\right]$ mating was used for this study. Mice were maintained on the segregating (129S4/SvJae; C57BL/6J) genetic background. To generate C57BL/6J background PcKOTsc1 mice, Tg (Nphs2-Cre), Tsc $1^{f /+}$ (129S4/SvJae; C57BL/6J) mice were crossed with $\mathrm{C} 57 \mathrm{BL} / 6 \mathrm{~J}$ mice, followed by 6 sequential generations of backcrossing with $\mathrm{C} 57 \mathrm{BL} / 6 \mathrm{~J}$ mice. Offspring from the backcrossed $[\mathrm{Tg}$ (Nphs2-Cre), $\left.T s c 1^{f /+}\right] \times\left[T s c 1^{A / f]}\right]$ mating were used for the study. For podocytespecific Raptor-KO diabetic mice, C57BL/6J background [Tg (Nphs2-Cre), Raptor $\left.{ }^{l /+}\right]$ mice were crossed with BKLS background $d b / m$ mice to generate male $[\mathrm{Tg}$ (Nphs2-Cre), Raptorfl/+,$d b /+] \mathrm{F}_{1}$ mice (49). [Tg (Nphs2-Cre), Raptor ${ }^{\ell /+}$, $d b /+] \mathrm{F}_{1}$ male mice were crossed with $d b / m$ females, followed by additional sequential generations of backcrossing with $d b / m$ mice. $\mathrm{F}_{3}[\mathrm{Tg}$ (Nphs2-Cre), Raptor $\left.{ }^{[/+}, d b /+\right]$ male mice were crossed with $\mathrm{F}_{3}$ females [Raptor $\left.{ }^{l /+}, d b /+\right]$ to generate $\left[\operatorname{Tg}(N p b s 2-C r e)\right.$, Raptor $\left.{ }^{l /+}, d b / d b\right]$ mice. To minimize genetic variations, the full and half siblings were grouped into control ([Raptor $\left.{ }^{f /+}, d b /+\right]$ and $\left[\right.$ Raptor $\left.\left.^{l / f l}, d b /+\right]\right), \mathrm{DM}\left(\left[\right.\right.$ Raptor $\left.^{f /+}, d b / d b\right]$ and $\left[\right.$ Raptor $\left.\left.\mathrm{r}^{f / f l}, d b / d b\right]\right)$, and DM Raptor $^{+/-}\left(\left[\operatorname{Tg}(N p h s 2\right.\right.$-Cre $)$, Raptor $\left.\left.{ }^{\ell /+}, d b / d b\right]\right)$ mice and used for the study. Animal experiments were conducted following a protocol approved by the University of Michigan Committee on the Use and Care of Animals (UCUCA).

Immunohistochemistry. For immunohistochemistry, we used both paraffin-embedded and frozen tissue sections in mouse models. For paraffinembedded tissue, the renal tissues were fixed by transcardiac perfusion with PBS containing $4 \%$ paraformaldehyde. For frozen sections, transcardiac perfusion with PBS containing $20 \mathrm{mM} \mathrm{NaF}$ was performed to eliminate blood cells and to protect protein dephosphorylation during sample preparation. Staining was visualized by indirect/direct immunofluorescence or DAB. For human samples, acetone-fixed tissue sections were used for indirect immunofluorescence staining.

Immunoelectron microscopy. For immunogold staining, renal tissues were fixed by transcardiac perfusion with PBS containing $4 \%$ paraformaldehyde. Tissues were dehydrated and embedded in LR white (Electron Microscopy Sciences). Ultrathin kidney cortical sections (70 $\mathrm{nm}$ ) were mounted onto Formvar/carbon-coated nickel grids (Electron Microscopy Sciences). Aldehyde quenching with $0.05 \mathrm{~mol} / 1$ glycine and antigen retrieval with citrate buffer $\left(95^{\circ} \mathrm{C}\right.$ for 10 minutes) were performed before blocking with normal donkey serum, bovine serum albumin, cold water fish gelatin, and Tween 20 (Electron Microscopy Sciences). The tissues were incubated with rabbit anti-nephrin antibody overnight at $4{ }^{\circ} \mathrm{C}$ in blocking buffer plus 0.2\% BSA-c (Aurion; Electron Microscopy Sciences). After washing, sections were incubated with a donkey anti-rabbit antibody conjugated to $10 \mathrm{nmol} / 1$ gold particles at 1:20. After rinsing, grids were fixed in $2.5 \%$ glutaraldehyde in $0.1 \mathrm{~mol} / \mathrm{l}$ phosphate buffer and post-stained with uranyl acetate and lead citrate.

$E M$ analysis. The renal samples were fixed with Sorensen's phosphate buffer containing $4 \%$ paraformaldehyde and $2.5 \%$ glutaraldehyde. The processed samples were analyzed by Philips CM100 TEM and AMRAY 1910 field emission scanning EM (FEG-SEM).

In vivo physiological studies. Blood glucose levels were measured using an automated blood glucose reader (Accu-Chek, Roche). Urinary albumin and creatinine were determined using mouse-specific ELISA (Albuwell M kit) and Creatinine Companion kit (Exocell). Mouse serum creatinine (Arbor Assays) and GPT (Cayman Chemical) concentrations were also measured by ELISA. Glomerular tuft area, PAS-positive mesangial area, and other pixel densities obtained by immunohistochemical experiments were measured by ImageJ software. The number of total glomerular or WT1-positive glomerular cells (podocytes) was counted in glomerular cross-sections $(4 \mu \mathrm{m})$.

Isolation of glomeruli and $m R N A$ quantification by RT-PCR analysis. Pure glomeruli were collected by magnetic bead-based isolation. The transcardiac perfusion was performed with PBS containing precleaned beads (Dynabeads, Invitrogen). The perfused renal cortex was briefly digested with collagenase, and the glomeruli choked with beads were isolated by magnets (IMag, BD). Total RNA was purified and used for reverse transcription by SuperScript First-Strand Synthesis System (Invitrogen). Quantitative PCR was carried out with specific primers (Supplemental Information). For quantitative analysis, the samples were normalized to Hprt1 (hypoxanthine phosphoribosyl transferase 1) gene expression using the $\Delta \Delta C T$ value method.

Western blot analysis. The isolation of glomeruli was performed as above. Purified glomeruli from one mouse were lysed in lysis buffer $(10 \mathrm{mM}$ Tris$\mathrm{HCl}$ [pH 7.5], $100 \mathrm{mM} \mathrm{NaCl}, 1 \% \mathrm{NP}-40,50 \mathrm{mM} \mathrm{NaF}, 20 \mathrm{mM} \beta$-glycerophosphate, 2 mM EDTA, $1 \mathrm{mM}$ DTT, $1 \mathrm{mM}$ PMSF, $10 \mu \mathrm{g} / \mathrm{ml}$ leupeptin, and $10 \mu \mathrm{g} / \mathrm{ml}$ aprotinin) as a lysate sample. Lysates were then boiled in SDS sample buffer (20 mM Tris [pH 6.8] 8\% SDS, 0.05\% bromophenol blue, $40 \%$ glycerol, $20 \%$ 2-mercaptoethanol) and subjected to SDS-PAGE and Western blotting according to standard techniques.

Statistics. All data were analyzed by ANOVA with Scheffe's post-hoc tests. Asterisks represent statistically significant differences. $P$ values less than 0.05 were considered significant.

\section{Acknowledgments}

We thank A. Saltiel and F. Brosius (University of Michigan, Ann Arbor) for discussion and C. Tsui, R. Verma, and M. Uhm (University of Michigan, Ann Arbor) for technical assistance. We thank C. Edwards, S. Meshinchi, and D. Sorenson (Microscopy and Image Analysis Laboratory, University of Michigan, Ann Arbor) for EM analyses. This work was supported by a George M. O’Brien Renal Center Developmental Research (DR)/Pilot and Feasibility (P\&F) grant (to K. Inoki), a Juvenile Diabetes Research Foundation Award (to K. Inoki), NIH grants DK083491 (to K. Inoki) and GM051586 (to K.-L. Guan), and the Excellence Initiative of the German Federal and State Governments (EXC 294 5o T.B. Huber).

Received for publication August 15, 2010, and accepted in revised form March 8, 2011.

Address correspondence to: Ken Inoki, Life Sciences Institute, University of Michigan, 210 Washtenaw Avenue, Ann Arbor, Michigan 48109, USA. Phone: 734.763.1102; Fax: 734.647.9702; E-mail: inokik@umich.edu. Or to: Kun-Liang Guan, UCSD Moores Cancer Center, 3855 Health Sciences Drive, La Jolla, California 920930815, USA. Phone: 858.822.7945; Fax: 858.822.5433; E-mail: kuguan@ucsd.edu.
1. Inoki K, Corradetti MN, Guan KL. Dysregulation of the TSC-mTOR pathway in human disease. Nat Genet. 2005;37(1):19-24.

2. White KE, et al. Podocyte number in normotensive type 1 diabetic patients with albuminuria. Diabetes. 2002;51(10):3083-3089.

3. Pagtalunan ME, et al. Podocyte loss and progressive glomerular injury in type II diabetes. J Clin Invest. 1997;99(2):342-348.
4. Lemley KV, et al. Podocytopenia and disease severity in IgA nephropathy. Kidney Int. 2002;61(4):1475-1485.

5. Kestila M, et al. Positionally cloned gene for a novel glomerular protein - nephrin - is mutated in congenital nephrotic syndrome. Mol Cell. 1998;1(4):575-582.

6. Ruotsalainen V, et al. Nephrin is specifically located at the slit diaphragm of glomerular podocytes. Proc Natl Acad Sci U S A. 1999;96(14):7962-7967.

7. Boute N, et al. NPHS2, encoding the glomerular protein podocin, is mutated in autosomal recessive steroid-resistant nephrotic syndrome. Nat Genet. 2000;24(4):349-354.

8. Susztak K, Raff AC, Schiffer M, Bottinger EP. Glucose-induced reactive oxygen species cause apoptosis of podocytes and podocyte depletion at the onset of diabetic nephropathy. Diabetes. 2006;55(1):225-233.

9. Li JJ, et al. Podocyte biology in diabetic nephropa- 
thy. Kidney Int Suppl. 2007;(106):S36-S42.

10. Ziyadeh FN, Wolf G. Pathogenesis of the podocytopathy and proteinuria in diabetic glomerulopathy. Curr Diabetes Rev. 2008;4(1):39-45.

11. Wullschleger S, Loewith R, Hall MN. TOR signaling in growth and metabolism. Cell. 2006; 124(3):471-484.

12. Hay N, Sonenberg N. Upstream and downstream of mTOR. Genes Dev. 2004;18(16):1926-1945.

13. Sancak Y, et al. The Rag GTPases bind raptor and mediate amino acid signaling to mTORC1. Science. 2008;320(5882):1496-1501.

14. Inoki K, Li Y, Xu T, Guan KL. Rheb GTPase is a direct target of TSC2 GAP activity and regulates mTOR signaling. Genes Dev. 2003;17(15):1829-1834.

15. Long X, Lin Y, Ortiz-Vega S, Yonezawa K, Avruch J. Rheb binds and regulates the mTOR kinase. Curr Biol. 2005;15(8):702-713.

16. Kwiatkowski DJ. Tuberous sclerosis: from tubers to mTOR. Ann Hum Genet. 2003;67(pt 1):87-96.

17. Crino PB, Nathanson KL, Henske EP. The tuberous sclerosis complex. N Engl J Med. 2006; 355(13):1345-1356.

18. Nagai K, et al. Gas6 induces Akt/mTOR-mediated mesangial hypertrophy in diabetic nephropathy. Kidney Int. 2005;68(2):552-561.

19. Lloberas N, et al. Mammalian target of rapamycin pathway blockade slows progression of diabetic kidney disease in rats. J Am Soc Nephrol. 2006; 17(5):1395-1404

20. Yang Y, et al. Rapamycin prevents early steps of the development of diabetic nephropathy in rats. Am J Nephrol. 2007;27(5):495-502.

21. Sataranatarajan K, et al. Regulation of elongation phase of mRNA translation in diabetic nephropathy: amelioration by rapamycin. Am J Pathol. 2007; 171(6):1733-1742.

22. Mori H, et al. The mTOR pathway is highly activated in diabetic nephropathy and rapamycin has a strong therapeutic potential. Biochem Biophys Res Commun. 2009;384(4):471-475.

23. Moeller MJ, Sanden SK, Soofi A, Wiggins RC, Holzman LB. Podocyte-specific expression of cre recombinase in transgenic mice. Genesis. 2003;35(1):39-42.

24. Inoki K, Li Y, Zhu T, Wu J, Guan KL. TSC2 is phosphorylated and inhibited by Akt and suppresses mTOR signalling. Nat Cell Biol. 2002;4(9):648-657.

25. Siragy HM, Inagami T, Ichiki T, Carey RM. Sustained hypersensitivity to angiotensin II and its mechanism in mice lacking the subtype-2 (AT2) angiotensin receptor. Proc Natl Acad Sci U S A. 1999; 96(11):6506-6510

26. Naito T, et al. Angiotensin type 2 receptor actions contribute to angiotensin type 1 receptor blocker effects on kidney fibrosis. Am J Physiol Renal Physiol. 2010;298(3):F683-F691.

27. Benndorf RA, et al. Angiotensin II type 2 receptor deficiency aggravates renal injury and reduces survival in chronic kidney disease in mice. Kidney Int. 2009;75(10):1039-1049.

28. Steffes MW, Schmidt D, McCrery R, Basgen JM. Glomerular cell number in normal subjects and in type 1 diabetic patients. Kidney Int. 2001;59(6):2104-2113.

29. Dalla Vestra M, Masiero A, Roiter AM, Saller A, Crepaldi $G$, Fioretto $P$. Is podocyte injury relevant in diabetic nephropathy? Studies in patients with type 2 diabetes. Diabetes. 2003;52(4):1031-1035.

30. Gaede P, Vedel P, Parving HH, Pedersen O. Intensified multifactorial intervention in patients with type 2 diabetes mellitus and microalbuminuria: the Steno type 2 randomised study. Lancet. 1999; 353(9153):617-622.

31. Rosenstock J, Raskin P. Early diabetic nephropathy: assessment and potential therapeutic interventions. Diabetes Care. 1986;9(5):529-545.

32. Fountain KJ, et al. Analysis of creatinine in mouse and rat serum by ion exchange high performance liquid chromatography for in vivo studies of renal function. J Chromatogr B Analyt Technol Biomed Life Sci. 2007;846(1-2):245-251.

33. Shankland SJ. The podocyte's response to injury: role in proteinuria and glomerulosclerosis. Kidney Int. 2006;69(12):2131-2147.

34. Wiggins RC. The spectrum of podocytopathies: a unifying view of glomerular diseases. Kidney Int. 2007;71(12):1205-1214

35. Bonnet F, Cooper ME, Kawachi H, Allen TJ, Boner G, Cao Z. Irbesartan normalises the deficiency in glomerular nephrin expression in a model of diabetes and hypertension. Diabetologia. 2001;44(7):874-877.

36. Doublier $S$, et al. Nephrin expression is reduced in human diabetic nephropathy: evidence for a distinct role for glycated albumin and angiotensin II. Diabetes. 2003;52(4):1023-1030.

37. Langham RG, et al. Proteinuria and the expression of the podocyte slit diaphragm protein, nephrin, in diabetic nephropathy: effects of angiotensin converting enzyme inhibition. Diabetologia. 2002; 45(11):1572-1576.

38. Sung SH, Ziyadeh FN, Wang A, Pyagay PE, Kanwar YS, Chen S. Blockade of vascular endothelial growth factor signaling ameliorates diabetic albuminuria in mice. J Am Soc Nephrol. 2006;17(11):3093-3104.

39. Reidy K, Susztak K. Epithelial-mesenchymal transition and podocyte loss in diabetic kidney disease. Am J Kidney Dis. 2009;54(4):590-593.

40. Li Y, Kang YS, Dai C, Kiss LP, Wen X, Liu Y. Epithelial-to-mesenchymal transition is a potential pathway leading to podocyte dysfunction and proteinuria. Am J Pathol. 2008;172(2):299-308.

41. Rincon-Choles $\mathrm{H}$, et al. ZO-1 expression and phosphorylation in diabetic nephropathy. Diabetes. 2006;55(4):894-900.

42. Yamaguchi Y, et al. Epithelial-mesenchymal transition as a potential explanation for podocyte depletion in diabetic nephropathy. Am J Kidney Dis. 2009; 54(4):653-664.

43. Toyoda M, Najafian B, Kim Y, Caramori ML, Mauer M. Podocyte detachment and reduced glomerular capillary endothelial fenestration in human type 1 diabetic nephropathy. Diabetes. 2007;56(8):2155-2160.

44. Lindenmeyer MT, et al. Proteinuria and hyperglycemia induce endoplasmic reticulum stress. J Am Soc Nephrol. 2008;19(11):2225-2236

45. Oyadomari S, et al. Targeted disruption of the Chop gene delays endoplasmic reticulum stress-mediated diabetes. J Clin Invest. 2002;109(4):525-532.

46. Liu XL, Done SC, Yan K, Kilpelainen P, Pikkarainen $\mathrm{T}$, Tryggvason K. Defective trafficking of nephrin missense mutants rescued by a chemical chaperone. J Am Soc Nephrol. 2004;15(7):1731-1738.

47. Ulianich L, et al. ER stress is associated with dedifferentiation and an epithelial-to-mesenchymal transition-like phenotype in $\mathrm{PC} \mathrm{Cl} 3$ thyroid cells. J Cell Sci. 2008;121(pt 4):477-486.

48. Ozcan U, et al. Chemical chaperones reduce ER stress and restore glucose homeostasis in a mouse model of type 2 diabetes. Science. 2006;313(5790):1137-1140.

49. Polak P, Cybulski N, Feige JN, Auwerx J, Ruegg MA, Hall MN. Adipose-specific knockout of raptor results in lean mice with enhanced mitochondrial respiration. Cell Metab. 2008;8(5):399-410.

50. Guertin DA, et al. Ablation in mice of the mTORC components raptor, rictor, or mLST8 reveals that mTORC2 is required for signaling to Akt-FOXO and PKCalpha, but not S6K1. Dev Cell. 2006; 11(6):859-871.

51. Gödel M, et al. Role of mTOR in podocyte function and diabetic nephropathy in humans and mice. J Clin Invest. 2011;121(6):2197-2209.

52. Zhong Q, et al. Role of ER stress in EMT of alveolar epithelial cells: effects of misfolded surfactant protein [published online ahead of print December 17, 2010]. Am J Respir Cell Mol Biol. doi:10.1165/ rcmb.2010-0347OC.

53. Hutt DM, et al. Reduced histone deacetylase 7 activity restores function to misfolded CFTR in cystic fibrosis. Nat Chem Biol. 2010;6(1):25-33.

54. Kouraklis G, Theocharis S. Histone deacetylase inhibitors: a novel target of anticancer therapy (review). Oncol Rep. 2006;15(2):489-494.

55. Qi X, Hosoi T, Okuma Y, Kaneko M, Nomura Y. Sodium 4-phenylbutyrate protects against cerebral ischemic injury. Mol Pharmacol. 2004;66(4):899-908.

56. Braissant $\mathrm{O}$. Current concepts in the pathogenesis of urea cycle disorders. Mol Genet Metab. 2010; 100(suppl 1):S3-S12.

57. Diekmann F, Campistol JM. Conversion from calcineurin inhibitors to sirolimus in chronic allograft nephropathy: benefits and risks. Nephrol Dial Transplant. 2006;21(3):562-568.

58. Torras J, et al. Rapamycin has dual opposing effects on proteinuric experimental nephropathies: is it a matter of podocyte damage? Nephrol Dial Transplant. 2009;24(12):3632-3640.

59. Franz S, Regeniter A, Hopfer H, Mihatsch M, Dickenmann M. Tubular toxicity in sirolimus- and cyclosporine-based transplant immunosuppression strategies: an ancillary study from a randomized controlled trial. Am J Kidney Dis. 2010;55(2):335-343.

60. Welsh GI, et al. Insulin signaling to the glomerular podocyte is critical for normal kidney function. Cell Metab. 2010;12(4):329-340.

61. Kobayashi N. Mechanism of the process formation; podocytes vs. neurons. Microsc Res Tech. 2002; 57(4):217-223.

62. Tavazoie SF, Alvarez VA, Ridenour DA, Kwiatkowski DJ, Sabatini BL. Regulation of neuronal morphology and function by the tumor suppressors Tsc1 and Tsc2. Nat Neurosci. 2005;8(12):1727-1734

63. Mori $\mathrm{H}$, et al. Critical role for hypothalamic mTOR activity in energy balance. Cell Metab. 2009; 9(4):362-374

64. Ma J, et al. Mammalian target of rapamycin regulates murine and human cell differentiation through STAT3/p63/Jagged/Notch cascade. J Clin Invest. 2010;120(1):103-114.

65 . Karbowniczek M, et al. The evolutionarily conserved TSC/Rheb pathway activates Notch in tuberous sclerosis complex and Drosophila external sensory organ development. J Clin Invest. 2010;120(1):93-102.

66. Niranjan T, et al. The Notch pathway in podocytes plays a role in the development of glomerular disease. Nat Med. 2008;14(3):290-298.

67. Ishikura N, et al. Notch-1 activation and dendritic atrophy in prion disease. Proc Natl Acad Sci U S A. 2005;102(3):886-891.

68. Murea M, et al. Expression of Notch pathway proteins correlates with albuminuria, glomerulosclerosis, and renal function. Kidney Int. 2010;78(5):514-522.

69. Timmerman LA, et al. Notch promotes epithelialmesenchymal transition during cardiac development and oncogenic transformation. Genes Dev. 2004; 18(1):99-115.

70. Sharma K, et al. Increased renal production of transforming growth factor-beta 1 in patients with type II diabetes. Diabetes. 1997;46(5):854-859.

71. Yamamoto T, Nakamura T, Noble NA, Ruoslahti E, Border WA. Expression of transforming growth factor beta is elevated in human and experimental diabetic nephropathy. Proc Natl Acad Sci U S A. 1993;90(5):1814-1818.

72. Barletta GM, Kovari IA, Verma RK, Kerjaschki D, Holzman LB. Nephrin and Neph1 co-localize at the podocyte foot process intercellular junction and form cis hetero-oligomers. J Biol Chem. 2003; 278(21):19266-19271.

73. Holzman LB, St John PL, Kovari IA, Verma R, Holthofer H, Abrahamson DR. Nephrin localizes to the slit pore of the glomerular epithelial cell. Kidney Int. 1999;56(4):1481-1491.

74. Mazzucco G, et al. Different patterns of renal damage in type 2 diabetes mellitus: a multicentric study on 393 biopsies. Am J Kidney Dis. 2002;39(4):713-720. 